\title{
Relación teoría-práctica y actividad común como focos para resolver problemas de educación: la significación del conocimiento de la educación no ampara el modelo dual
}

\section{Theory-practice relationship and common activity as focuses to solve education problems: the signification of knowledge of education does not cover the dual model}

\author{
José Manuel Touriñán López ${ }^{1}$ \\ Premio Internacional Educa-Redipe 2019 (Trayectoria profesional) \\ ${ }^{1}$ Universidad de Santiago de Compostela josemanuel.tourinan@usc.es
}

Recibido: 30/10/2020

Aceptado: $30 / 11 / 2020$

\section{Copyright $($ )}

Facultad de CC. de la Educación y Deporte. Universidad de Vigo

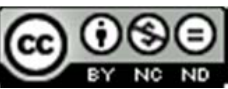

Dirección de contacto:

José Manuel Touriñán López

Departamento de Pedagogía y Didáctica

Facultad de Ciencias de la Educación

Campus Vida, s/n

15782 Santiago de Compostela

\begin{abstract}
Resumen
Este trabajo insiste en la importancia del estudio de la relación teoría-práctica para obtener el conocimiento especializado y específico de la educación: el conocimiento pedagógico.

Se establece una relación entre significación y conocimiento de la educación por medio de la capacidad de resolución de problemas para la intervención, y se debate su estructura y utilidad para la intervención a través de la relación teoría-práctica en cada corriente del conocimiento de la educación (marginal, subalternada y autónoma).

La significación como principio de metodología es un problema derivado de cómo se entiende la relación teoría-práctica en cada corriente del conocimiento de la educación para justificar el conocimiento válido.

Al ejecutar la actividad común externa, mejoramos y entrenamos las actividadescapacidades internas: sin la actividad es imposible educar y gracias a ella se hace posible que el educando sea agente actor y cada vez mejor agente autor de su propios proyectos y actos.

Veremos cómo la función pedagógica genera intervención desde las actividades comunes. Y podremos concluir que la actividad común y la relación teoría-práctica son focos para resolver problemas de educación desde la intervención pedagógica, que siempre implica conocimiento y acción.
\end{abstract}

\section{Palabras clave}

Conocimiento de la Educación, Modelo de Crecimiento del Conocimiento de la Educación, Significación del Conocimiento de la Educación, Principios de Metodología de Investigación, Relación Teoría-Práctica, Función Pedagógica, Teorías de la Educación. 


\section{Abstract}

This work insists on the importance of the study of theory-practice relationship to obtain specialized and specific knowledge of education: pedagogical knowledge. Education is a real field that people may know in different ways, forms, and types. Several types of knowledge and rationality are useful for making knowledge of education: philosophical theories, practical theories, applied research, substantive theories have let them build it. To a higher extent, knowledge of education has already made particular and specific concepts.

This study establishes differences between knowledge of education and knowledge of disciplines which are used in educative process. Besides this, it emphasizes and upholds the Educational Knowledge Growth Model.

The second half of this work continues to explain the different possibilities that each current of knowledge of education has, for solving the problems which arise in the intervention, regarding to theory-practice relationship.

All this has been made by focusing the discussion about the theory- practice connection in three different pedagogical currents (marginal, subaltern, and autonomous).

Signification as a principle of methodology is a problem derived from how the theorypractice relationship is understood in each current of knowledge of education to justify valid knowledge.

By executing the external common activity, we improve and train the internal activities-capacities: without the activity it is impossible to educate and through the activity it becomes possible for the educatee to be an actor-agent and an increasingly better author-agent of his own projects and acts.

We shall see how the pedagogical function generates intervention by means of internal and external common activities. And we can conclude that common activity and theory-practice relationship are focuses to solve education problems from pedagogical intervention, which always implies knowledge and action.

\section{Key Words}

Knowledge of Education, Educational Knowledge Growth Model, Signification of Knowledge of Education, Principles of Research Methodology, Theory-Practice Relationship, Pedagogical Function, Theories of Education.

\section{INTRODUCCIÓN}

La educación es un ámbito de realidad susceptible de ser conocido. En el conocimiento de la educación se utilizan actualmente teorías filosóficas, teorías prácticas, investigaciones aplicadas y teorías sustantivas y se han generado ya términos propios con significación intrínseca a la educación.

El conocimiento de la educación ha crecido a través del tiempo. Se ha convertido en un conocimiento especializado. En este trabajo se aborda la distinción entre los conocimientos especializados de cada área cultural que se enseña y el conocimiento específico del estudio de la educación como objeto de conocimiento. Además, se estudian diversos modelos de evolución del conocimiento de la educación, enfatizando el interés y utilidad del modelo de crecimiento.

El trabajo insiste en la importancia del estudio de la relación teoría-práctica para obtener el conocimiento especializado y específico de la educación: el conocimiento pedagógico. 
Por último, se establece una relación entre significación y conocimiento de la educación por medio de la capacidad de resolución de problemas para la intervención, y se debate su estructura y utilidad para la intervención a través de la relación teoríapráctica en cada corriente del conocimiento de la educación (marginal, subalternada y autónoma).

En Pedagogía, como disciplina de conocimiento de la educación, podemos hablar con propiedad de significado del término "educación" y podemos hablar de significado del conocimiento de la educación. Pero, además, podemos hablar de significación como principio de investigación pedagógica. La significación como principio de investigación apunta a la validez y a la fiabilidad del significado, al valor metodológico del significado.

La significación como principio de investigación pedagógica (signification, sense of) no se confunde con la significatividad (significativity, relevance, significance, significant), ni con el significado (meaning, concept, definition) de "educación". La significación, como tal principio, se asocia a la validez del conocimiento de la educación y se define como la capacidad de resolución de problemas (capacity of solving problems) que se le atribuye al conocimiento de la educación en cada corriente desde la perspectiva de la relación teoría-practica para la actividad educativa.

La significación como principio de metodología, no es un problema de Pedagogía cognitiva focalizado en la teoría de resolución de problemas (Problem Solving Theory) que la Psicología ha fundamentado para explicar el razonamiento humano. Es verdad que la teoría de la psicología cognitiva de resolución de problemas ha hecho posible la construcción de teorías prácticas de la educación usadas para mejorar el modo de conocer de cada alumno. Ahora bien, cuando hablamos de la significación como principio de metodología, estamos hablando de un problema de epistemología del conocimiento de la educación, cuyo estudio corresponde a la Pedagogía general como disciplina que estudia los fundamentos de la metodología en educación, entre otros problemas. La significación como principio de metodología es un problema derivado de cómo se entiende la relación teoría-práctica en cada corriente del conocimiento de la educación para justificar el conocimiento válido.

Por otra parte, como expondré en el epígrafe dedicado a la función pedagógica, nos educamos con la actividad común interna. Pero, además, nos educamos por medio de la actividad común externa (estudiando, jugando, trabajando, indagando-explorando, interviniendo y relacionándonos con el yo, el otro y lo otro), porque al ejercer una concreta actividad común externa activamos las capacidades comunes internas, las entrenamos, las ejercitamos, las ejercemos y las mejoramos para hacer bien cada actividad común externa. La actividad común externa, por principio de actividad, activa la actividad común interna en cada ejecución concreta de la actividad común externa, sea esta jugar, estudiar, trabajar, indagar, intervenir o relacionar. Al ejecutar la actividad común externa, mejoramos y entrenamos las actividades-capacidades internas: sin la actividad es imposible educar y gracias a ella se hace posible que el educando sea agente actor y cada vez mejor agente autor de su propios proyectos y actos.

Y esto es lo que analizo en este artículo sobre el conocimiento de la educación, por medio de los siguientes apartados:

- Diversidad de paradigmas y homogeneidad de criterios en el debate acerca del conocimiento de la educación 
- El conocimiento de la educación determina el concepto de ámbito de educación sobre el conocimiento de áreas culturales

- Modelos de evolución del conocimiento de la educación

- Corrientes del conocimiento de la educación

- Conocimiento de la educación y conocimiento pedagógico

- Intervención pedagógica y significación del conocimiento de la educación en cada corriente desde la relación teoría-práctica

- El modelo dual que separa teoría y práctica en la formación no resuelve bien la relación teoría-práctica, porque cada intervención pedagógica tiene que integrar conocimiento y acción

- La función pedagógica genera intervención desde las actividades comunes

- La actividad común y la relación teoría-práctica son focos para resolver problemas de educación desde la Pedagogía.

\section{DIVERSIDAD DE PARADIGMAS Y HOMOGENEIDAD DE CRITERIOS}

En el año 1982 Peters y Ceci dieron a conocer los resultados de su investigación acerca de la fiabilidad de los criterios que utilizan los editores de revistas científicas para seleccionar las investigaciones publicables. El trabajo consistía en analizar las respuestas obtenidas, al enviar a 12 prestigiosas revistas de Psicología investigaciones para publicar que ya habían sido publicadas recientemente en ellas, si bien se había desfigurado de forma no substantiva el título del artículo y el resumen de este. En esta investigación (Peters y Ceci, 1982) se comprobó, de manera sorprendente, que nueve de los doce manuscritos no fueron detectados por el editor o por el equipo de revisión como anteriormente publicados en la Revista respectiva. De los nueve no detectados como previsiblemente publicados, ocho fueron rechazados a causa de "serios problemas de metodología". Peters y Ceci concluyen su investigación, denunciando la ausencia de criterio homogéneo para la corrección y la escasa firmeza de criterio en los correctores.

En el año 1987, W.K. Davis realiza un estudio teórico acerca de la debilidad de los paradigmas en la investigación pedagógica y concluye que, si bien es verdad que somos capaces de establecer un sofisticado nivel en términos de metodología de la investigación y de las técnicas de evaluación, también es cierto que muchas de las cuestiones de investigación responden más frecuentemente a ocurrencias oportunistas respecto del entorno que a un sistemático y permanente interrogatorio del modo de encarar el sentido y meta de la intervención pedagógica (Davis, 1987).

La ausencia de unificación de paradigmas en la investigación pedagógica ha sido denunciada en muy diversos trabajos y los manuales internacionales de investigación pedagógica dejan constancia de esta idea (Wittrock, 1986; Keeves, 1988). Para Schulman (1986) la ausencia de un paradigma singular de investigación no es un signo patológico del campo, ni una señal de peligro para el campo de estudio. El problema, como dice Husen (1988), habría que verlo, más bien, en las posiciones dogmáticas y reduccionistas que limiten el conocimiento de la educación a la capacidad de resolución de problemas que se establezca desde una determinada concepción, pues eso equivaldría a negar la posibilidad de avance en el sistema conceptual de un campo. 
La diversidad de criterio, e incluso la polémica en la investigación, no deben interpretarse de manera descontextualizada. Controversia y polémica no son sinónimos de ausencia de resultados. Desde el contexto de la investigación pedagógica no puede olvidarse que, en cualquier caso, esta polémica es una polémica de expertos acerca de un conocimiento especializado. En el fondo, con esta polémica, no sólo se pone de manifiesto la importancia del tema de "la educación como objeto de conocimiento" en la investigación pedagógica, sino que, además, se fortalece la relación entre la función pedagógica y el conocimiento de la educación. Como dice Berliner (1986), el pedagogo experto es el objeto de investigación, porque él es el que está utilizando el conocimiento de la educación de manera eficaz en su intervención, y esto es, en definitiva, lo que se pretende con el conocimiento de la educación: que sea adecuado para explicar, interpretar y decidir la intervención pedagógica (Biesta, Allan y Edwards, 2014; Boavida y García del Dujo, 2007; Rabazas, 2014; García Aretio, Ruiz Corbella y García Blanco, 2009; Carr, 2006; Pring, 2014; Gimeno, 1982a y 1982b; García Carrasco y García del Dujo, 2001; Touriñán, 2014; Touriñán y Longueira, 2016).

En nuestra opinión la polémica no supone descrédito para el tema de estudio, porque es posible establecer parámetros acerca del conocimiento de la educación que fundamenten pautas intersubjetivables de análisis de las diferentes posiciones que se mantienen respecto del conocimiento de la educación. Así las cosas, la cuestión no es la polémica y la diversidad de paradigmas, sino más precisamente la posibilidad de unificación de los criterios de análisis; o, dicho de otro modo, el problema no es la diversidad de paradigmas, sino la homogeneidad de criterios respecto de la identidad y evolución del conocimiento de la educación (Touriñán, 2016, 2018a y 2018b).

\section{EL CONOCIMIENTO DE LA EDUCACIÓN DETERMINA EL CONCEPTO DE ÁMBITO DE EDUCACIÓN SOBRE EL CONOCIMIENTO DE ÁREAS CULTURALES}

El nivel de las investigaciones pedagógicas actuales permite afirmar que hay razones suficientes para distinguir y no confundir en el lenguaje técnico:

- el conocimiento de la educación, y

- los conocimientos de las áreas culturales.

Es verdad que, desde el punto de vista antropológico, la educación es cultura y, por tanto, tiene sentido afirmar que la función del profesional de la educación es transmitir cultura. Pero, si además afirmamos que los términos educacionales carecen de contenido propio, los conocimientos de las diversas áreas culturales se convierten en el eje de toda actividad pedagógica hasta el extremo de que los mismos profesionales de la educación llegan a aceptar que su formación es simplemente el conocimiento de esas áreas culturales.

El análisis detenido del contexto pedagógico da pie para sostener que el conocimiento de las áreas culturales no es el conocimiento de la educación, porque (Touriñán, 2017a):

a) Si bien es verdad que una buena parte de los objetivos de la educación tiene algo que ver con los contenidos de las áreas culturales en la enseñanza, el ámbito de los objetivos no se agota en los ámbitos de las áreas culturales, ni siquiera en la docencia. La función pedagógica, referida a la docencia, no se agota en saber la información 
cultural correspondiente a un tema de un área cultural en una clase; antes bien, la función pedagógica se pone de manifiesto cuando se sabe qué tipos de destrezas, hábitos, actitudes, etc., de los diversos dominios que señalan las taxonomías, se están potenciando al trabajar de manera especial en ese tema. La cuestión, en la docencia, no es saber tanto sobre un área como el especialista, sino saber qué objetivos de conocimiento se logran y cómo se logran al enseñar un tema del área y qué destrezas, hábitos, actitudes, conocimientos y competencias estamos desarrollando al enseñar ese tema.

b) La identificación del conocimiento de las áreas culturales con el conocimiento de la educación fomenta una situación pedagógica insostenible: la tendencia a evaluar el rendimiento escolar fundamentalmente por los niveles de información cultural de área. Sin que ello signifique que cualquier contenido sea puramente formal y sirva para alcanzar cualquier tipo de destreza, es posible afirmar que, aunque no con el mismo nivel de eficacia, desde el punto de vista pedagógico, con uno sólo de los temas culturales del programa que debe estudiar un alumno de Secundaria, por ejemplo, se podrían poner en marcha las estrategias pedagógicas conducentes al logro de casi todos los objetivos educativos del programa, a excepción de la información cultural específica del área.

c) Incluso identificando conocimiento de la educación y conocimiento de áreas culturales, se puede entender que hay un determinado conocimiento de la educación, hablando de la enseñanza, que no es el conocimiento de las áreas culturales: el conocimiento de la transmisión de los conocimientos de esas áreas culturales. La educación tendría efectivamente como misión, por ejemplo, la transmisión de conocimiento acerca de la Historia. En este caso, que ese conocimiento sea fiable y válido es problema de los historiadores y de los investigadores de esa área cultural; el conocimiento de la educación para la enseñanza sería, en este caso, el conocimiento de las estrategias de intervención.

Los conocimientos teóricos, tecnológicos y práxicos que se constituyen en objetivos de conocimiento de la enseñanza, no los crea el profesional de la educación. Son los investigadores de cada área cultural los que los crean. Al profesional de la educación le corresponde con fundamento de elección técnica decidir: si el educando puede aprenderlos; si son coherentes con la representación conceptual de la intervención; si tienen fundamento teórico, tecnológico y práxico, según el caso; cual es el método de enseñanza adecuado y qué destrezas, hábitos y actitudes se pueden desarrollar con la enseñanza de ese conocimiento. Es decir, el profesional de la educación domina los conocimientos teóricos, tecnológicos y práxicos del área cultural que va a enseñar; pero, como profesional de la educación, domina el conocimiento de la educación que le permite justificar y explicar la conversión de esos conocimientos de un área cultural en objetivo o instrumento de la intervención pedagógica (Touriñán, 2013c).

El conocimiento de la educación capacita al profesional de la docencia, por ejemplo, no sólo para establecer el valor educativo de un contenido cultural y participar en el proceso de decidir su conversión en fin o meta de un determinado nivel educativo, sino también para establecer programas de intervención ajustados a hechos y decisiones pedagógicas que hagan efectiva la meta propuesta.

Hablar de conocimiento de la educación no implica, por tanto, interrogarse directamente acerca de los saberes de las áreas culturales. Cuando hablamos de "el 
conocimiento de la educación", es más apropiado preguntarse por qué determinados conocimientos se constituyen en meta o instrumento de la acción educativa o por qué es educable la dimensión cognitiva del hombre. Y así como de los conocimientos de cada área cultural podrían hablarnos, según el caso y con propiedad, el historiador, el geógrafo, el matemático, el físico, etc., porque son especialistas en cada una de esas áreas de conocimiento, no nos cabe ninguna duda que responder adecuadamente a si tal o cual contenido histórico, matemático, físico, etc., debe constituirse en el contenido de la acción educativa que realizamos con un determinado sujeto, o a como cultivar su sentido crítico, exige interrogarse acerca de la educación como objeto de conocimiento. En la primera conjetura, los conocimientos de áreas culturales -la Historia, la Matemática, la Física, etc.- son el objeto científico de estudio; en los dos casos de la segunda conjetura, la transmisión misma, la influencia que se ejerce, se convierte en objeto específico de reflexión científica.

De acuerdo con las reflexiones realizadas anteriormente, hablar de "conocimiento de la educación" es lo mismo que interrogarse acerca de la educación como objeto de conocimiento, lo que equivale a formularse una doble pregunta:

- Qué es lo que hay que conocer para entender y dominar el ámbito de la educación; o lo que es lo mismo, cuales son los componentes del fenómeno educativo que hay que dominar para entender dicho fenómeno.

- Cómo se conoce ese campo; o, dicho de otro modo, qué garantías de credibilidad tiene el conocimiento que podamos obtener acerca del campo de la educación.

Nos parece necesario distinguir conocimiento de áreas culturales y conocimiento de la educación porque, en la misma medida que el conocimiento de la educación va más allá de lo que se transmite, la función pedagógica -en el ámbito de la docenciacomienza a ser objeto de conocimiento especializado y específico. Precisamente por eso podemos definir la función pedagógica como ejercicio de tareas cuya realización requiere competencias adquiridas por medio del conocimiento de la educación.

Si no distinguimos conocimiento de áreas culturales y conocimiento de la educación, se sigue que, por ejemplo, la competencia profesional de los profesores se definiría erróneamente por el mayor o menor dominio del área cultural que van a enseñar. Este tipo de planteamientos genera consecuencias nefastas para estos profesionales:

- En primer lugar, como los conocimientos de áreas culturales que enseñan no los crearían los profesores, estos se percibirían a sí mismos como aprendices de los conocimientos de esas áreas que otros investigan.

- En segundo lugar, como la competencia profesional se definiría por el dominio del área cultural, se fomentaría el error de creer que el que más sabe es el que mejor enseña.

Si no confundimos conocimiento de áreas culturales y conocimiento de la educación, ni es verdad que el profesor es un aprendiz de las áreas culturales que enseña, ni es verdad que necesariamente el que más Historia sabe es el que mejor la enseña, ni es verdad que el que mejor domine una destreza es el que mejor enseña a otro a dominarla, a menos que, tautológicamente, digamos que la destreza que domina es la de enseñar.

Esto es así, porque cada una de esas actividades requiere distintas competencias y destrezas para su dominio, y la práctica y perfección en una de ellas no genera automáticamente el dominio de la otra.

En rigor lógico, hay que aceptar que el conocimiento de la educación es, pues, un conocimiento especializado que permite al especialista explicar, interpretar y decidir la 
intervención pedagógica propia de la función para la que se habilita, bien sea función de docencia, bien sea de apoyo al sistema educativo, o bien sea función de investigación.

Si repasamos las afirmaciones anteriores, parece obvio que la función pedagógica, por principio de significado, exige conocimiento especializado de la educación.

Por supuesto, es evidente que la función pedagógica no se reduce a la docencia; el colectivo profesional de los docentes es sólo una parte de los profesionales de la educación. Pero la distinción realizada entre conocimiento de áreas culturales y conocimiento de la educación nos permite distinguir e identificar a los profesionales de la educación y a las funciones pedagógicas (Touriñán, 2013a):

a) En el sistema educativo trabajan sociólogos, médicos, psicólogos y otros profesionales que reciben con propiedad la denominación de profesionales del sistema educativo, porque ejercen su profesión en y sobre el sistema educativo. Pero, además, existe un grupo de profesionales del sistema educativo que merecen con propiedad la denominación de profesionales de la educación; su tarea es intervenir, realizando las funciones pedagógicas para las que se han habilitado; el contenido propio del núcleo formativo en su profesión es el conocimiento de la educación. "Profesionales del sistema educativo" y "profesionales de la educación" son dos expresiones distintas con significado diferente; y tiene sentido afirmar que, no todo profesional del sistema educativo es profesional de la educación, en tanto en cuanto sólo el contenido de la formación profesional de este es siempre el conocimiento de la educación. Profesional de la educación es el especialista que domina los conocimientos teóricos, tecnológicos y prácticos de la educación que le permiten explicar, interpretar y decidir la intervención pedagógica propia de la función para la que está habilitado.

b) Si tomamos como referente las tareas y actividades que hay que realizar en el ámbito educativo, el conocimiento de la educación y el desarrollo del sistema educativo permiten identificar tres tipos de funciones pedagógicas, genéricamente (Touriñán, 1987c):

- Funciones pedagógicas de docencia, o funciones didácticas, identificadas básicamente con el ejercicio y dominio de destrezas, hábitos, actitudes y conocimientos que capacitan para enseñar en un determinado nivel del sistema educativo.

- Funciones pedagógicas de apoyo al sistema educativo. Son funciones que no se ocupan directamente de la docencia, aunque mejoren las posibilidades de ésta, porque su tarea es resolver problemas pedagógicos del sistema educativo que surgen con el crecimiento del mismo y del conocimiento de la educación, y que, de no subsanarse, paralizarían la docencia o dificultarían el logro social de una educación de calidad a través del sistema educativo, como es el caso de la organización escolar, la intervención pedagógico-social, la planificación educativa, etc.

- Funciones de investigación pedagógica, identificadas con el ejercicio y dominio de destrezas, hábitos, actitudes y conocimientos que capacitan para la validación y desarrollo de modelos de explicación, interpretación y transformación de intervenciones pedagógicas y acontecimientos educativos.

Cabría pensar que debiera añadirse la función educadora al cuadro de funciones pedagógicas, porque no es lo mismo educar que enseñar. Educar es, en efecto, la función más excelsa del pedagogo y esa función está asumida, desde la Pedagogía en 
cada una de las demás funciones, tanto desde la consideración de la educación como ámbito de conocimiento, como desde la consideración de la educación como acción. Ahora bien, dado que hablamos de funciones pedagógicas en sentido estricto, debemos mantener la diferencia entre Pedagogía y educación y, precisamente por esa distinción, sería un error atribuir la función de educador de manera particular al pedagogo de carrera, como si no hubiera educadores que no son pedagogos (Touriñán, 2015).

Y esta afirmación que acabo de hacer no debe tomarse como renuncia a la acción y a la competencia especializada y específica en la función pedagógica, sino como reconocimiento de responsabilidad compartida en la tarea educativa. Y así las cosas, salvando la responsabilidad compartida, también hemos de reconocer que en cualquier función pedagógica se incluyen competencias educativas, pues por principio de definición nominal y por principio de finalidad en la actividad, ejercemos funciones pedagógicas y eso quiere decir que lo son, porque usan el conocimiento de la educación para educar: no se trata de enseñar, investigar y apoyar al sistema educativo para cualquier cosa, sino de enseñar, investigar y apoyar lo que educa. En este discurso, la función educadora está presente como cualidad o sentido en las funciones pedagógicas de docencia, apoyo al sistema educativo e investigación, que son tres funciones pedagógicas distintas.

La distinción realizable entre conocimiento de áreas culturales y conocimiento de la educación nos permite distinguir e identificar a los profesionales de la educación como profesionales distintos de los profesionales del sistema educativo. Respecto de esta cuestión, hemos de decir que en el sistema educativo trabajan sociólogos, médicos, psicólogos, conductores, cocineros, arquitectos, etc. Estos profesionales reciben con propiedad la denominación de profesionales del sistema educativo, porque ejercen su profesión en y sobre el sistema educativo aplicando su conocimiento especializado sobre las cuestiones específicas del sistema educativo: el comedor escolar, la salud, el transporte, los edificios, etc. Pero, además, existe un grupo de profesionales del sistema educativo que merecen con propiedad la denominación de profesionales de la educación; su tarea es intervenir, realizando las funciones pedagógicas para las que se han habilitado; el contenido propio del núcleo formativo en su profesión, su conocimiento especializado, es el conocimiento de la educación. "Profesionales del sistema educativo" y "profesionales de la educación" son dos expresiones distintas con significado diferente; y tiene sentido afirmar que, no todo profesional del sistema educativo es profesional de la educación, en tanto en cuanto sólo el contenido de la formación profesional de este es siempre el conocimiento de la educación. Profesional de la educación es el especialista que domina los conocimientos teóricos, tecnológicos y prácticos de la educación que le permiten explicar, interpretar, transformar y decidir la intervención pedagógica propia de la función para la que está habilitado (Touriñán, 2017a).

Los profesionales de la educación realizan funciones de docencia, funciones pedagógicas de apoyo al sistema educativo y funciones de investigación, siempre con el objetivo último de educar en cada una de ellas. Las funciones pedagógicas de apoyo al sistema educativo son funciones referidas siempre a la intervención pedagógica, no se ocupan directamente de la docencia, aunque mejoren las posibilidades de ésta; su tarea es resolver problemas pedagógicos del sistema educativo que surgen con el crecimiento de este y del conocimiento de la educación, y que, de no subsanarse, paralizarían la docencia educativa o dificultarían el logro social de una educación de calidad a través 
del sistema educativo. Las funciones pedagógicas de apoyo al sistema educativo responden a la diferencia entre conocer, enseñar y educar $\mathrm{y}$, son, como en todos los ámbitos de realidad que tienen la doble condición de ámbito de conocimiento y de acción (caso de la educación), de dos tipos: el técnico de apoyo a la realización de la intervención pedagógica (como el inspector de educación o el director de centro educativo, entre otros) y el técnico especialista en la realización de la intervención pedagógica (como son el pedagogo que construye ámbitos de educación y diseños educativos, el orientador formativo-educacional, el pedagogo escolar, el pedagogo ambiental, el pedagogo laboral, el pedagogo social, el pedagogo familiar, por ejemplo). Estas funciones se resumen en el Cuadro 1.

Por otra parte, la distinción entre conocimientos de áreas culturales y conocimiento de la educación nos coloca también en una posición especial para establecer la distinción entre finalidades extrínsecas de la educación (metas educativas) y finalidades intrínsecas de la educación (metas pedagógicas). Tiene sentido establecer esta distinción dentro del sistema social y para el subsistema "educación" porque las finalidades intrínsecas son propias del subsistema, en tanto que derivan del conocimiento propio del subsistema educación (conocimiento de la educación) y, a su vez, las finalidades extrínsecas también son propias del subsistema, pero porque se incorporan al mismo después de ser elegidas (fin = valor elegido) para el subsistema por ser compatibles con él, aunque no nacen del conocimiento de la educación.

Así las cosas, podemos decir que los conocimientos teóricos, tecnológicos y práxicos (de la Literatura, la Historia, la Filosofía, la experiencia de vida, la Moral, las costumbres, etc.) de las diversas áreas culturales que se constituyen en objetivo de conocimiento de la enseñanza no los crean los profesionales de la educación con su conocimiento especializado (conocimiento de la educación); son los especialistas de cada una de esas áreas los que los crean y se "convierten" en metas social y moralmente legitimadas en esa sociedad. Precisamente por eso son candidato a meta de la educación. Si además de estar legitimadas social y moralmente, son elegidos, pasan a ser, no candidato a meta educativa, sino efectiva finalidad extrínseca.

Las finalidades intrínsecas, por su parte, son las que se deciden en el sistema y su contenido es conocimiento de la educación. La validez de sus enunciados no procede sin más de su carácter social y moralmente deseable, o de su validez en un área cultural, sino de las pruebas específicas del ámbito, es decir, a partir del significado que se les atribuye a los enunciados desde el sistema conceptual elaborado con el conocimiento de la educación.

Este mismo discurso exige, por coherencia, reconocer que hay un determinado tipo de metas (extrínsecas) que tienen un carácter histórico y variable, sometido a la propia evolución de lo socialmente deseable y al crecimiento del área cultural concreta a que pertenece (hoy no se enseñan las matemáticas de hace años, ni se les da el mismo valor dentro del currículum escolar; hoy no se enseñan las mismas "costumbres" que hace años, etc.). Hablamos aquí de los conocimientos de las disciplinas que forman parte de la educación. 
PROFESIÓN: actividad específica, con fundamento en conocimiento especializado, reconocida socialmente para cubrir necesidades sociales

FUNCIÓN PEDAGÓGICA: ejercicio de tareas cuya realización requiere competencias adquiridas por medio del conocimiento de la educación

\section{PROFESIONALES DEL SISTEMA EDUCATIVO}

ejercen su profesión en y sobre el sistema educativo aplicando su conocimiento especializado sobre las cuestiones específicas del sistema educativo: el comedor escolar, la salud, el transporte, los edificios,

etc. En el sistema educativo trabajan sociólogos, médicos, psicólogos, conductores, cocineros, arquitectos, etc.

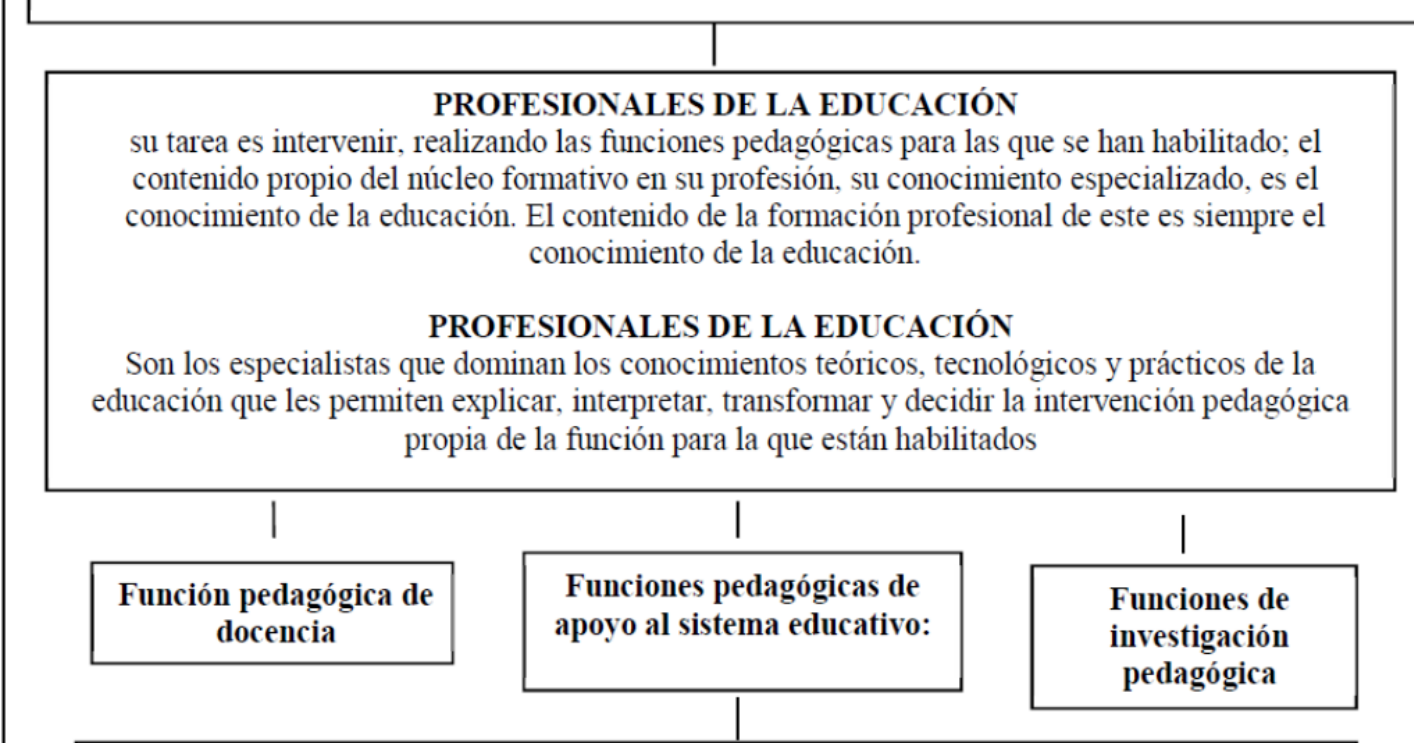

Técnico de apoyo a la realización de la intervención pedagógica (como el inspector de educación o el director de centro educativo, entre otros)

Técnico especialista en la realización de la intervención (como son el pedagogo que construye ámbitos de educación y diseños educativos, el orientador formativo-educacional, el pedagogo escolar, el pedagogo ambiental, el pedłgogo laboral, el pedagogo social, el pedagogo familiar, el asesor pedagógico, por ejemplo).

\section{FUNCIÓN DE EDUCAR}

PROCESOS MEDIADOS DE INTERVENCIÓN PEDAGÓGICA

(Procesos de autoeducación y procesos de heteroeducación formales, no formales e informales)

Cuadro 1. Profesionales de la educación y funciones pedagógicas. Fuente: Touriñán, 2020a, p. 145.

Además, hay otras finalidades intrínsecas, que tienen un carácter histórico y variable sometido a la propia evolución del conocimiento de la educación. Hablamos aquí del conocimiento de la educación derivado de la educación como objeto de conocimiento.

Ambos tipos de finalidades están sometidas al carácter histórico. Pero la respuesta es muy distinta -por el tipo de discurso que lo justifica-, cuando decimos que el hombre debe saber Historia para estar educado (finalidad extrínseca) y hay que desarrollar sentido crítico, porque sin él, el hombre no podrá educarse (finalidad intrínseca). En el 
primer caso el hombre estará más o menos educado; en el segundo, el hombre podrá educarse o no (necesidad lógica). Parece, por tanto, que una buena separación entre las finalidades intrínsecas y extrínsecas deriva de la distinción entre necesidad lógica de algo y necesidades psicológicas del nivel sociohistórico en el que se da ese algo (¿cuál es el hombre educado de cada época?).

Si nuestro discurso es correcto, tal como decíamos al principio de este apartado, es posible hablar y distinguir conocimientos de áreas culturales y conocimiento de la educación. Pero, además, como se ha razonado a lo largo de este epígrafe, conocer, enseñar y educar tienen significados distintos, la lógica de saber, no es la lógica de hacer saber y hay enseñanzas que no educan. Por eso, es importante distinguir entre la educación como objeto de conocimiento (el conocimiento de la educación; knowledge of education; education knowledge) y el conocimiento como objeto de educación (la educabilidad de nuestro conocimiento; the educability of our knowledge; knowledge education or cognitive education), si se nos permite la expresión (Touriñán, 2013b).

Para nosotros queda claro que:

- Hablar de los conocimientos de la educación (knowledges about education; educational knowledges; education knowledge) es lo mismo que hablar del conjunto de conocimientos teóricos, tecnológicos y prácticos que la investigación va consolidando acerca del ámbito de realidad que es la educación. Son en sí mismos conocimientos de un área cultural. Pero, en este caso, son el área cultural específica; la de la educación, que se convierte en sí misma en objeto de conocimiento (educación como objeto de conocimiento, como objeto cognoscible).

- Hablar de los conocimientos de las áreas culturales es hablar de los conocimientos teóricos, tecnológicos y prácticos que los especialistas de cada área -matemáticos, físicos, psicólogos, médicos, etc.- han ido consolidando con sus investigaciones.

- Hablar del conocimiento como objeto de educación (the educability of our knowledge; knowledge education or cognitive education) es hablar de una determinada parcela del conocimiento de la educación, aquella que nos permite intervenir para mejorar nuestro modo de conocer.

Hablar de conocimiento de la educación no implica interrogarse directamente acerca de los saberes de las áreas culturales. Cuando hablamos de "el conocimiento de la educación”, es más apropiado preguntarse por qué determinados conocimientos se constituyen en meta o instrumento de la acción educativa o por qué es educable la dimensión cognitiva del hombre. Y así como de los conocimientos de cada área cultural podrían hablarnos, según el caso y con propiedad, el historiador, el geógrafo, el matemático, el físico, el crítico de arte, etc., porque son especialistas en cada una de esas áreas culturales, no cabe duda que responder adecuadamente a si tal o cual contenido histórico, matemático, físico, artístico, etc., debe constituirse en el contenido de la acción educativa que realizamos con un determinado sujeto, o a cómo cultivar su sentido crítico, exige interrogarse acerca de la educación como objeto de conocimiento.

En el primer supuesto, los conocimientos de las áreas culturales -la historia, la matemática, la física, etc.- son el objeto científico de estudio; en los dos casos del segundo supuesto, la transmisión misma y la mejora de la capacidad de conocer se convierten en objeto específico de la reflexión científica en forma de Didáctica y de Pedagogía cognitiva, según el caso. Y así las cosas, el conocimiento como objeto de 
educación exige la investigación de la educación, es decir, exige que la educación se convierta en objeto de conocimiento, bien como Pedagogía cognitiva o bien como Didáctica, respectivamente, pero, además de responder a por qué se produjo un determinado acontecimiento educativo y a cómo se puede lograr un determinado acontecimiento educativo, hay que responder, también, a cómo se justifica ese acontecimiento como acontecimiento educativo y esta es una cuestión que sólo se responde desde el conocimiento que tenemos del concepto educación y el significado de "educación" se construye desde la Pedagogía. Esa es la pregunta desde la Pedagogía, no por mejorar nuestro modo de conocer, ni por mejorar nuestro modo de enseñar, sino la pregunta por la educación misma desde conceptos con significación intrínseca (autóctonos) al ámbito de conocimiento "educación". Conocer un área cultural no es enseñar, porque, como acabamos de ver, las competencias que se requieren en cada caso son distintas y enseñar no es educar, porque podemos afirmar que hay enseñanzas que no educan, con fundamento en el significado propio de esos términos.

Hay que asumir sin prejuicios que la Pedagogía es conocimiento de la educación y este se obtiene de diversas formas, pero, en última instancia, ese conocimiento, por principio de significación, sólo es válido si sirve para educar; es decir, para transformar la información en conocimiento y este en educación, desde conceptos con significación intrínseca al ámbito de educación. Por una parte, hay que saber en el sentido más amplio del término (sé qué, sé cómo y sé hacer); por otra parte, hay que enseñar (que implica otro tipo de saber distinto al de conocer las áreas de experiencia cultural; enseñar implica hacer saber a otros). Y, por si eso fuera poco, además, hay que educar, que implica, no sólo saber y enseñar, sino también dominar el carácter y sentido propios del significado de "educación", para aplicarlo a cada área de experiencia cultural con la que educamos. Cuando interpretamos el área de experiencia cultural desde la mentalidad pedagógica específica y desde la mirada pedagógica especializada ${ }^{1}$, nuestra preocupación intelectual nos permite distinguir entre "saber Historia", "enseñar Historia" y "educar con la Historia", entendida esta como una materia de área cultural que forma parte del currículo junto con otras y se ha convertido desde la Pedagogía en ámbito de educación.

El ámbito de educación, tal como se usa en este contexto de argumentación, no es un espacio físico, sino un concepto derivado de la valoración educativa del área de experiencia que utilizamos como instrumento y meta de educación. El ámbito de educación es resultado de la valoración educativa del área de experiencia que utilizamos

\footnotetext{
${ }^{1}$ Al pedagogo le compete hacer la intervención pedagógica con mirada especializada, para tener visión crítica de su método y de sus actos, y con mentalidad específica, para integrar la teoría en la práctica y resolver en la interacción el problema de educar. La mentalidad pedagógica es representación mental que hace el pedagogo de la acción de educar desde la perspectiva de la relación teoría-práctica; hace referencia a la capacidad de resolución de problemas que se le atribuye al conocimiento de la educación en cada corriente desde la perspectiva de la acción.

La mentalidad pedagógica es específica. No es general sobre la vida, sino sobre la educación como objeto cognoscible y realizable. Ni es una mentalidad filosófica de las cosmovisiones del mundo, de la vida y de los sentidos de vida posibles, ni es la mentalidad educativa que se ajusta a criterios de significado y orientación formativa temporal de educar. La mentalidad pedagógica es mentalidad fundada en la educación como objeto de conocimiento y por tanto en el conocimiento de la educación.

La mirada pedagógica es la representación mental que hace el profesional de la educación de su actuación técnica, es decir, de su actuación en tanto que pedagógica; se corresponde con la visión crítica que tiene el pedagogo de su método y de sus actos fundada en principios de intervención y principios de educación.

La mirada pedagógica es, por tanto, especializada, está focalizada a los problemas de educación y la competencia técnica de mirar pedagógicamente depende del conocimiento de la educación que se ha adquirido.
} 
para educar y por eso, desde la Pedagogía, en el concepto de ámbito de educación se integran el significado de educación, los procesos de intervención, las dimensiones de intervención y las áreas de experiencia y las formas de expresión, junto con cada acepción técnica de ámbito.

El ámbito de educación, que es siempre expresión del área cultural valorada como objeto e instrumento de educación integra los siguientes componentes: área de experiencia con la que vamos a educar, formas de expresión convenientes para educar con esa área, criterios de significado de educación reflejados en rasgos de carácter y sentido inherentes al significado de educar, dimensiones generales de intervención que vamos a utilizar en la educación, procesos de educación que deben seguirse y acepción técnica de ámbito. Integrar estos componentes es lo que hace el conocimiento de la educación con cada área cultural para hablar con propiedad conceptual de educar "con" un área cultural como concepto distinto de enseñar un área cultural y conocer un área cultural que forma parte del currículo.

Si no confundimos conocimiento de áreas culturales y conocimiento de la educación, ni es verdad que el profesor es un aprendiz de las áreas culturales que enseña, ni es verdad que necesariamente el que más Arte sabe es el que mejor lo enseña, ni es verdad que el que mejor domine una destreza es el que mejor enseña a otro a dominarla, a menos que, tautológicamente, digamos que la destreza que domina es la de enseñar, ni es verdad que, cuando se enseña, estamos utilizando siempre el contenido cultural como instrumento de logro del carácter y sentido propio del significado de educación, porque enseñar no es educar. Es objetivo de la Pedagogía transformar la información en conocimiento y el conocimiento en educación, construyendo ámbitos de educación desde las diversas áreas culturales, y precisamente por eso podemos decir que a la Pedagogía le corresponde valorar cada área cultural como educación y construirla como “ámbito de educación” (Touriñán, 2017b).

Esto es así, porque cada una de esas actividades requiere distintas competencias y destrezas para su dominio, y la práctica y perfección en una de ellas no genera automáticamente el dominio de la otra. En rigor lógico, hay que aceptar que el conocimiento de la educación es, pues, un conocimiento especializado que permite al pedagogo explicar, interpretar y decidir la intervención pedagógica adecuada al área cultural que es objeto de enseñanza y educación, según el caso.

\section{MODELOS DE EVOLUCIÓN DEL CONOCIMIENTO DE LA EDUCACIÓN}

El objetivo, cuando se analiza el crecimiento del conocimiento de la educación, es establecer un esquema de interpretación que nos permita, con criterio lógico, comprender la distinta consideración que el conocimiento de la educación tiene o ha tenido. Se intenta describir las propiedades que permiten caracterizar diferentes momentos de la consideración de la educación como objeto de conocimiento. El objetivo no es la productividad en cada uno de esos momentos; lo que preocupa, no es la cantidad de investigaciones realizadas, sino, más bien, saber cómo es considerada la educación como objeto de conocimiento en distintas investigaciones. Interesa más el análisis del supuesto que permite entender la educación como objeto de conocimiento de un modo y no de otro, que la fecundidad de la hipótesis, es decir, que los conceptos y 
precisiones terminológicas que se establecen sucesivamente, una vez se ha aceptado el supuesto. Lo que interesa especialmente es entender la propia transformación de la educación como objeto de conocimiento y su progresiva adecuación al ámbito que estudia. Interesa, en definitiva, saber cuáles son las propiedades que definen en diversos momentos a la educación como objeto de conocimiento y cómo se justifica que ésa es la investigación que debe hacerse del objeto de conocimiento "educación".

Este tipo de cuestiones se recogen ordinariamente bajo la denominación genérica de "paradigma de investigación". Los estudios de Khun $(1978,1979)$ acerca del término citado y los análisis que posteriormente se han realizado acerca de la ruptura epistemológica (cambio de supuesto) que conllevan los cambios de paradigma (Bachelard, 1973) son sobradamente conocidos en la literatura especializada. A pesar de que es un dato significativo a considerar que, en el trabajo de Khun acerca de la estructura de las revoluciones científicas, Masterman detectó 22 usos diferentes del término paradigma (Masterman, 1970), los paradigmas pueden entenderse como marcos de interpretación, o modos de pensar acerca de algo; en sí mismos no son teorías, pero una vez que el investigador se compromete o asume uno específico, le puede conducir al desarrollo de teorías (Gage, 1963).

Con anterioridad hemos dedicado tiempo al estudio de la educación como objeto de conocimiento (Touriñán 1987a y 1987b; Rodríguez Martínez 1989). Nuestra preocupación básica fue establecer un marco de interpretación que nos permita comprender la distinta consideración que el conocimiento de la educación tiene o ha tenido. El trabajo en el punto de partida mantiene la convicción de que la preocupación pedagógica ha existido siempre aunque no fuese científica, la ocupación pedagógica, también, aunque no fuese profesionalizada; lo que no ha existido siempre es la misma consideración para la función pedagógica, porque el conocimiento de la educación no ha tenido siempre la misma significación, entendida ésta como principio metodológico de investigación, y por tanto, como la capacidad que tiene ese conocimiento de resolver problemas de la educación. Así las cosas, los criterios establecidos para elaborar el marco de interpretación han de permitir, según el tipo de respuesta a ellos, configurar una mentalidad pedagógica específica y, por tanto, un modo peculiar de relacionar la teoría y la práctica (Touriñán, 1988-89 y 1991).

\subsection{Modelos Bibliométricos y Lingüí́sticos}

Entre los modelos que se han utilizado para analizar la evolución del conocimiento de la educación conviene destacar los denominados modelos Bibliométricos y Lingüísticos.

Los modelos lingüísticos tratan de resolver la evolución del conocimiento de la educación, clasificando diversas concepciones de aquel bajo enunciados y conceptos específicos que en diversos momentos se han utilizado para el conocimiento de la educación.

En la aplicación de este de modelo se realiza un esfuerzo ciertamente considerable para poder aislar las diferentes posiciones que se dan sobre la educación como objeto de conocimiento. Sin embargo, somos de la opinión de que esta no es la forma más adecuada de tratar el problema de la educación como objeto de conocimiento, a pesar de que los términos "pedagogía", "ciencia de la educación" y "ciencias de la educación" tienen un significado referido a momentos históricos diferentes de esa evolución 
(Mialaret, 1977; Husen, 1979; Mitter, 1981; Vázquez Gómez, 1981, 1984; Quintana, 1983; Sarramona, 1985; Touriñán 1987b).

La tesis de los modelos lingüísticos es plausible, porque, si cada término atribuido en cada época histórica al conocimiento de la educación fuera distinto, la evolución lingüística supondría explícitamente la evolución epistemológica (en este caso la evolución del conocimiento de la educación). Pero no es posible resolver el problema de la evolución del conocimiento de la educación a partir de la clasificación de las diversas posiciones en virtud de enunciados y términos específicos que en diversos momentos se han utilizado, porque la hipótesis del modelo lingüístico exigiría, para su aplicación a la evolución del conocimiento, que los mismos términos no pudieran ser referentes de significados objetivamente contrapuestos acerca del conocimiento de la educación, ni en el mismo momento, ni en momentos históricos diferentes. En puridad, sólo de ese modo el modelo lingüístico podría dar respuesta satisfactoria a la evolución del conocimiento de la educación.

Bajo los modelos lingüísticos se avanza el conocimiento respecto del significado de enunciados tales como Pedagogía es ciencia o Pedagogía es más que ciencia o Pedagogía es menos que ciencia, pues estos modelos ponen al conocimiento de la educación en relación con la experiencia y la práctica, la investigación y el ámbito de la normatividad. Pero los modelos lingüísticos no pueden obviar el hecho constatado de que el significado de los términos no guarda en absoluto relación causal con el complejo simbólico-físico del lenguaje: ni el significado está en las palabras como algo físico, ni el lenguaje representa directamente las cosas.

De este modo, con los modelos lingüísticos, se introduce un factor de confusión en la evolución del conocimiento de la educación, porque:

- Los términos y enunciados no suponen de por sí necesariamente evolución del conocimiento de la educación.

- Algunos términos, que se atribuyen a épocas distintas de evolución, están coimplicados por su significado en un mismo modo de entender el conocimiento de la educación y no suponen, por tanto, evolución.

- El mismo término y enunciado adquiere significación distinta en momentos diferentes, y viceversa, términos distintos pueden tener el mismo significado. De tal manera que, respecto de la evolución del conocimiento de la educación, el mismo término y enunciado podría designar posiciones objetivamente contrapuestas respecto del modo de entender la educación como objeto de conocimiento.

Por otra parte, desde el punto de vista de la sociología del conocimiento, se están prodigando las investigaciones bibliométricas (Escolano, 1983; Pérez Alonso-Geta, 1985). Pero, si bien es verdad que este tipo de estudios proporciona datos acerca de la evolución del conocimiento de la educación, también lo es que son datos centrados en el incremento de la producción, en la productividad de un ámbito; o, dicho de otro modo, en la fecundidad de una hipótesis, más que en la modificación, innovación y cambio de hipótesis, que, en rigor, son las variaciones que determinan la evolución del conocimiento de un ámbito. 


\subsection{Modelo Tradicional de Evolución del Conocimiento de la Educación}

En la evolución del conocimiento de la educación, se acepta tradicionalmente que es posible establecer tres etapas, cada una de ellas con su propio planteamiento. Esta clasificación, que se conoce como modelo tradicional de evolución del conocimiento de la educación, fue resumida por G. Avanzini (1977).

- Etapa de la filosofía. En esta etapa el conocimiento que se legitima como conocimiento de la educación es estrictamente filosófico, de las finalidades de vida.

- Etapa de la ciencia de la educación. El conocimiento que se legitima como conocimiento de la educación es estrictamente positivista, de los medios para fines dados.

- Etapa de las ciencias de la educación. El campo de la educación es suficientemente amplio y complejo como para que diversas ciencias desempeñen su cometido de estudio.

Entendemos que este modelo, al que se le ha dedicado atención en otros trabajos (Touriñán 1987a y 1987b) debe ser descartado como tipificación de la evolución del conocimiento de la educación por muy diversas consideraciones que exponemos de forma sintética, a continuación.

El modelo tradicional mantiene que la preponderancia de una determinada concepción acerca de la educación como objeto de conocimiento (planteamiento básico de la etapa) y la especialización progresiva del conocimiento de la educación, son los ejes que determinan las tres etapas $\mathrm{y}$, por tanto, la evolución del conocimiento de la educación.

Esta posición es francamente verosímil. Pues la especialización configura modos distintos de entender el objeto de conocimiento. Sin embargo, el modelo tradicional no cubre esta función de evolución del conocimiento de la educación con precisión, porque carece de rigor lógico (pertinence) y de significatividad (relevance, significativity).

El modelo tradicional no tiene rigor lógico, porque, si lo que define una etapa es la preponderancia de un tipo de pensamiento (Filosofía, ciencia, o ciencias), deja abierta la posibilidad de clasificar cada obra concreta de pensamiento en dos etapas distintas. En efecto, cada obra puede incluirse en la etapa en la que predomina la forma de pensamiento utilizada en esa obra, y también puede incluirse en la etapa correspondiente al momento en que se escribió la obra, aunque el pensamiento predominante en ese momento no sea el mismo de la obra.

Si hoy escribimos sobre educación una obra con mentalidad de etapa de la Filosofía, puede clasificarse en esa primera etapa y puede clasificarse dentro de la última etapa, porque la hemos escrito en el momento de vigencia de esta tercera etapa. Esta ambigüedad reduce la significatividad de nuestra hipotética obra, porque su valor relativo en la evolución del conocimiento de la educación es distinto según se incluya en una u otra etapa, e, incluso, en algún caso, por efecto de la tendencia predominante, podría pasar desapercibida o rechazada como no significativa por ir "contra corriente" o estar "fuera de corriente".

Rechazo el modelo tradicional, porque utiliza etapas y corrientes de manera tal que una determinada obra es susceptible de inclusión en dos etapas distintas. Pero, fundamentalmente, rechazamos el modelo tradicional, porque entre su etapa de la 
ciencia de la educación y su etapa de las ciencias se mantiene la misma consideración general de la educación como objeto de conocimiento: en ambos casos la educación se resuelve en términos de otra ciencia. Esas dos etapas no suponen dos corrientes de pensamiento distinto acerca del conocimiento de la educación. Ambas etapas coinciden en la posibilidad del estudio científico subalternado de la educación. Ambas etapas niegan la posibilidad del estudio científico autónomo de la educación. Ambas etapas se diferencian entre sí, porque, en la etapa de "la ciencia de la educación", la educación es un marco de referencia sin significado intrínseco que se resuelve utilizando los principios de una sola disciplina generadora; en la etapa de las "ciencias de la educación" se admiten diversas disciplinas generadoras. El techo del modelo tradicional es la negación del estudio científico autónomo de la educación, y, por consiguiente, hablando con propiedad, el modelo tradicional es sólo el modelo de los estudios científicos subalternados de la educación.

Resulta plausible afirmar que primero fue la Filosofía, después la ciencia y luego las ciencias de la educación. Pero no debemos olvidar que la preponderancia de una determinada idea sobre otra es un criterio de estimación social, no un criterio epistemológico. Si se toma como criterio epistemológico, estamos afirmando que el planteamiento filosófico sería una especie a extinguir; un saber primitivo indiferenciado que va siendo vaciado progresivamente por las ciencias particulares. La realidad de los hechos no confirma tal cosa. Existen estudios actuales que prueban que la Filosofía surgió desde el comienzo como una disciplina diferenciada de las restantes (Palop, 1981, pp. 46-52); los problemas que plantean los filósofos y los científicos son distintos (Rey, 1959, pp. 37-38; Strong, 1966, pp. 7-8), lo cual quiere decir que el descenso del número de personas dedicadas a los problemas filosóficos no altera la pertinencia lógica de las preocupaciones intelectuales en las que se ocupan.

\subsection{Modelo de Crecimiento del Conocimiento de la Educación}

En el tema que nos ocupa ahora -la evolución de la educación como objeto de conocimiento-, de lo que se trata es de poner de manifiesto los medios por los cuales el conocimiento de la educación asegura su productividad de un modo específico y se transforma en la misma medida que ese modo de producción no se adapta plenamente a la compleja realidad que pretende conocer: la educación.

Del mismo modo que un organismo vivo se autorregula y transforma a efectos de obtener una mejor adaptación a las circunstancias, y el conocimiento de su crecimiento es el conocimiento de ese dinamismo orgánico, el modo de conocimiento de la educación crece. Es una organización que, una vez configurada con respecto a su objeto de conocimiento -la educación-, produce un determinado tipo de respuestas (conocimientos acerca de la educación). Puede perfeccionarse el modo de obtener respuestas sin variar el supuesto de conocimiento del que se parte (crecimiento simple); este es el modo típico de crecimiento dentro de cada concepción y permite desarrollar subetapas de crecimiento. Pero, además, puede perfeccionarse el modo de obtener respuestas, variando el supuesto de conocimiento del que se parte, porque el objeto que hay que conocer se considera con otro nivel de complejidad (crecimiento por innovación); este es el modo típico de crecimiento inter-concepciones y permite, por tanto, distinguirlas. 
En el modelo de crecimiento hay evidentemente un supuesto organicista: el de pensar analógicamente el desarrollo de un campo sistémico (la educación) como un crecimiento orgánico.

La economía, la organización y los estudios acerca del desarrollo de la ciencia han aplicado el modelo de crecimiento; hasta tal punto que toda política de planificación avanzada en cualquier campo tiene fundamento directo o indirecto en el modelo de crecimiento (Denison, 1968; O.C.D.E., 1968; Kindelberger, 1965; Schumpeter, 1949; Simon, 1957,1964; Etzioni, 1964; Churchman, 1961; Bertalanffy, 1976, 1979).

La teoría y la práctica de las reformas de las estructuras han tomado un sentido nuevo más concreto bajo el efecto del análisis de los sistemas (Morin, 1984; Wilden, 1972; Piaget, 1977; Luhman, 1983).

El modelo de crecimiento, a través de sus diversas manifestaciones, ha consolidado dos tipos de crecimiento: crecimiento simple o crecimiento por productividad del supuesto y crecimiento por innovación o crecimiento por cambio de supuesto (Touriñán 1987a y 1987b).

Dentro del crecimiento simple se incluyen diversos modos de aumentar la producción de conocimientos desde la organización configurada, es decir, sin variar el supuesto de partida. Bien aplicando la organización configurada a todos los problemas del campo a conocer (crecimiento simple extensivo); bien aumentando la producción en los diversos aspectos que pueden ser tratados por medio de la organización configurada (crecimiento simple intensivo). O bien reorganizando la corriente, sistematizando los problemas a tratar y/o mejorando (no sustituyendo) el modo de intervenir en la realidad a conocer (crecimiento simple intrínseco) (Touriñán 1987a y 1987b; Rodríguez Martínez, 1989).

La mejora del conocimiento dentro del supuesto aceptado se entiende como progreso; el cambio de supuesto supone siempre una innovación que afecta a la estructura básica del conocimiento del que se parte. El cambio de supuesto o de paradigma suele ser revolucionario, de ahí que sea en este modo de crecimiento en donde tenga sentido hablar de ruptura epistemológica (Bachelard, 1973,1974; Kuhn, 1979).

A pesar de lo que acabamos de decir, debemos tener en cuenta que los cambios de supuesto no se producen de modo inmediato, sino que, por el contrario, supone siempre un período de enfrentamiento entre lo que bajo el supuesto inicial era "ciencia normal" y el nuevo paradigma que se va configurando como el modo más adecuado para tratar los problemas que desde la "ciencia normal" no encontraban una explicación o resolución satisfactoria (por ejemplo la teoría de la evolución de las especies de Darwin). Esto quiere decir que una parte de los conocimientos producidos por el supuesto vigente hasta aquel momento van a ser rebatidos, otra parte se va a explicar de otra forma más ajustada al nuevo supuesto, y otra parte de ellos van a considerarse como obsoletos. Además, las investigaciones con cambio de supuesto van a centrarse en problemas que en el anterior supuesto carecían de significación o tenían escasa importancia. En nuestro caso concreto, el crecimiento del conocimiento por innovación supone un cambio en la consideración de la educación como objeto de conocimiento (Touriñán, 2017a). 


\section{CORRIENTES DEL CONOCIMIENTO DE LA EDUCACIÓN}

Por analogía con la evolución de otros saberes y por aplicación del modelo de crecimiento al conocimiento de la educación se distinguen, en la actualidad, tres corrientes distintas en la evolución del conocimiento de la educación. Las tres corrientes de la educación se denominan, según la consideración que hacen de la educación como objeto de conocimiento, del siguiente modo (Touriñán, 2016):

- Corriente marginal o experiencial.

- Corriente subalternada o de los estudios científicos de la educación.

- Corriente autónoma o de la ciencia de la educación.

Cada una de estas corrientes se distingue de las otras por su respuesta a las siguientes cuestiones:

- la consideración de la educación como objeto de estudio,

- el tipo de conocimiento que se va a obtener para saber educación,

- el modo de resolver el acto de intervención,

- la posibilidad o no de estudio científico y de la ciencia de la educación.

Cada una de estas corrientes ha aportado conocimientos acerca de la educación en absoluto despreciables. Sus logros son la base de su fuerza dentro del gremio de los profesionales de la educación. Cada corriente marca un techo de conocimiento, crea un patrón de justificación de la acción pedagógica y establece unos límites a la capacidad de resolución de problemas del conocimiento de la educación. El discurso pedagógico de cada corriente establece para la intervención una relación teoría-práctica diferente, que caracteriza la función pedagógica. El discurso pedagógico, la función pedagógica y la intervención pedagógica se entienden de modo distinto en cada corriente, porque las respuestas a los criterios configuran mentalidades pedagógicas distintas, tal como se expresa en el Cuadro 2.

Debe aclararse, con respecto al adjetivo marginal que, cuando decimos corriente marginal, no estamos afirmando desprecio hacia la Pedagogía en esa corriente. Sería absolutamente erróneo atribuir esa intencionalidad a los partidarios de la corriente marginal. Hablando con precisión, los partidarios de esta corriente entienden que todo estudio de la educación hay que hacerlo como ellos lo hacen; estudiar la educación no es estudiar un contexto devaluado; ni estudiarlo de un modo devaluado. Al contrario, la educación es valiosa y le aplican los modos más valiosos de conocer, pero incluso así es un estudio de carácter marginal en el sentido económico del término.

En el contexto económico, análisis marginal es el análisis económico centrado en zonas límite más bien que en la gama completa de fenómenos estudiados. Es decir, el análisis marginal estudia la utilidad de una unidad más que la gama completa de fenómenos estudiados (Touriñán, 1987b). 


\begin{tabular}{|c|c|c|c|}
\hline $\begin{array}{c}\text { Criterios } \\
\text { discriminantes }\end{array}$ & $\begin{array}{c}\text { Corriente marginal } \\
\text { Estudios filosóficos } \\
\text { cosmovisionarios }\end{array}$ & $\begin{array}{c}\text { Corriente de } \\
\text { subalternación } \\
\text { Estudios interpretativos } \\
\text { cientificos y filosóficos }\end{array}$ & $\begin{array}{c}\text { Corriente autónoma } \\
\text { Estudios de Pedagogía como } \\
\text { disciplina con autonomía } \\
\text { funcional }\end{array}$ \\
\hline $\begin{array}{l}\text { Consideración de la } \\
\text { educación como } \\
\text { objeto de estudio }\end{array}$ & $\begin{array}{l}\text { La educación no es } \\
\text { un objeto de estudio } \\
\text { genuino. Es una } \\
\text { actividad práctica }\end{array}$ & $\begin{array}{l}\text { La educación es un objeto } \\
\text { de estudio genuino que se } \\
\text { resuelve en términos de las } \\
\text { disciplinas generadoras }\end{array}$ & $\begin{array}{l}\text { La educación es un objeto de } \\
\text { estudio genuino que permite } \\
\text { generar conceptos propios del } \\
\text { ámbito }\end{array}$ \\
\hline $\begin{array}{c}\text { Tipo de } \\
\text { conocimiento a } \\
\text { obtener para saber de } \\
\text { educación }\end{array}$ & $\begin{array}{l}\text { El conocimiento } \\
\text { esencial es el de los } \\
\text { fines de vida } \\
\text { deseables }\end{array}$ & $\begin{array}{l}\text { El conocimiento esencial } \\
\text { es el de los medios para } \\
\text { fines dados o elaborados } \\
\text { práxicamente desde la } \\
\text { educación }\end{array}$ & $\begin{array}{c}\text { El conocimiento esencial } \\
\text { es el de fines y medios } \\
\text { lógicamente implicados en el } \\
\text { proceso }\end{array}$ \\
\hline $\begin{array}{c}\text { Modo de resolver } \\
\text { el acto de } \\
\text { intervención }\end{array}$ & $\begin{array}{l}\text { La intervención } \\
\text { se resuelve } \\
\text { experiencialmente }\end{array}$ & $\begin{array}{c}\text { La intervención se } \\
\text { resuelve en prescripción } \\
\text { de reglas validadas con } \\
\text { las teorias } \\
\text { interpretativas }\end{array}$ & $\begin{array}{l}\text { La intervención requiere } \\
\text { generar principios de } \\
\text { intervención pedagógica: } \\
\text { establecer vinculaciones y } \\
\text { prescribir reglas validadas } \\
\text { con las teorias sustantivas }\end{array}$ \\
\hline $\begin{array}{l}\text { Posibilidad de } \\
\text { estudio científico } \\
\text { y de la ciencia } \\
\text { de la educación }\end{array}$ & $\begin{array}{l}\text { No es posible el } \\
\text { estudio cientifico de } \\
\text { la educación porque } \\
\text { es una actividad } \\
\text { práctica y singular }\end{array}$ & $\begin{array}{c}\text { Es posible el estudio } \\
\text { científico de la } \\
\text { educación. Hay ciencias } \\
\text { de la educación }\end{array}$ & $\begin{array}{l}\text { Es posible la ciencia de la } \\
\text { educación. Hay Pedagogía } \\
\text { como disciplina autónoma } \\
\text { que genera conceptos con } \\
\text { significación intrínseca al } \\
\text { ámbito educación }\end{array}$ \\
\hline
\end{tabular}

Cuadro 2. Corrientes del conocimiento de la educación. Fuente: Touriñán, 2016, p. 109

Si bien el motivo no es la utilidad económica, en el contexto pedagógico, el carácter marginal de la Pedagogía quiere decir que el estudio de la educación es visto como una parte más de otro objeto de estudio. No es una preocupación intelectual aparte, sino solo una parte de otras preocupaciones intelectuales: el saber, la vida buena, la felicidad, la moralidad, la idea de hombre. Es estudio marginal en el sentido técnico, es un beneficio complementario derivado de la cosmovisión del mundo y de la vida.

La corriente marginal defiende básicamente que la educación no es un objeto de estudio genuino, es decir, no tiene un propósito distinto y aparte del de otras preocupaciones intelectuales. Es, concretamente, una parte de otra preocupación intelectual -las finalidades de la vida- y una actividad práctica cuyo conocimiento se resuelve experiencialmente.

Corriente subalternada del conocimiento de la educación, quiere decir que la subordinación es la condición que se le asigna al conocimiento de la educación (Touriñán, 1987b). El supuesto básico de este planteamiento afirma que la educación es un objeto de estudio genuino, es decir, tiene un propósito distinto al de otras preocupaciones intelectuales. Su objetivo es guiar la acción. Ahora bien, como objeto de conocimiento la educación se resuelve utilizando exclusivamente los principios elaborados por las disciplinas científicas generadoras.

En la corriente de subalternación, el conocimiento de la educación es científico y subordinado (subalterno, está subalternado), porque la estructura de justificación e interpretación de las reglas que se construyen para intervenir se resuelve exclusivamente 
con el soporte científico de las teorías de las disciplinas generadoras. Es la validez de las vinculaciones establecidas en las disciplinas generadoras, lo que garantiza la validez de las reglas de intervención educativa. El conocimiento de la educación en esta corriente está subordinado a la disciplina generadora.

La corriente autónoma del conocimiento de la educación propugna que el punto esencial del conocimiento pedagógico es el tratamiento específico del acto pedagógico y no las cosmovisiones del mundo y de la vida. Frente a la corriente de subalternación, se defiende la necesidad de buscar la significación intrínseca de los conceptos educacionales y se postula la autonomía funcional del conocimiento de la educación.

Autonomía funcional quiere decir posibilidad de concebir un campo de conocimiento que se desarrolla, no como consecuencia de presiones y recomendaciones externas provenientes de otros campos dotados de estructura teórica consolidada, sino como resultado de regulaciones internas del propio campo de conocimiento, de tal manera que la teoría de ese campo quede limitada por los conceptos, hipótesis y metodologías del propio campo y no por las teorías de otros campos. Autonomía funcional no equivale a la defensa de absoluta independencia, es compatible con una fecunda relación interdisciplinar y con la defensa del principio de dependencia disciplinar. Cada una de esas disciplinas es disciplina, porque usa las formas de conocimiento adecuadas a la mejor explicación y comprensión de la complejidad objetual de su ámbito de conocimiento; y es autónoma, porque crea su propio campo conceptual y sus pruebas. Sus conceptos surgen del estudio específico del ámbito que analizan y las relaciones que descubren establecen qué proposiciones son significativas en cada disciplina. Cuando la autonomía es funcional, no es incompatible con la existencia de relaciones de dependencia entre disciplinas.

Desde la perspectiva de la autonomía funcional, dependencia y subalternación no son lo mismo, porque lo probado por las disciplinas generadoras no queda probado pedagógicamente de manera automática y porque utilizar principios de las disciplinas generadoras en educación no es lo mismo que desarrollar principios de intervención pedagógica. Cuando hay autonomía funcional, los conceptos de cada disciplina matriz, generadora, son lógicamente distintos de los de otras disciplinas generadoras y reclaman, por tanto, elaboración teórica, tecnológica y práctica propia.

En la corriente autónoma, la función pedagógica es generadora de principios. La función pedagógica no es sólo utilizadora de principios de disciplinas generadoras. Preparar a las personas para la intervención pedagógica es hacerlas diestras en la elaboración de propuestas de intervención, pero eso exige también hacerlas diestras en la elaboración de esquemas de interpretación de la intervención, atendiendo al carácter y sentido de la educación y generando principios de intervención desde los elementos estructurales de la misma.

En cada corriente se genera una mentalidad pedagógica distinta. Entendemos mentalidad como sinónimo de Weltanschauung, cosmovisión, representación mental de la acción de educar desde la perspectiva de la relación teoría-práctica. La corriente es el marco de interpretación de cómo pensamos que es el conocimiento de la educación. La función pedagógica se identifica con el ejercicio de tareas cuya realización requiere competencias adquiridas por medio del conocimiento de la educación. El discurso pedagógico se entiende como el conjunto ordenado de razonamientos con fundamento en el conocimiento de la educación que permite explicar, interpretar y decidir la 
intervención pedagógica propia de la función para la que se está habilitado. Por último, la intervención pedagógica se define como el acto intencional destinado a desarrollar fines y medios que se justifican con fundamento en el conocimiento de la educación. Para los efectos de este discurso es importante destacar que (Touriñán, 2017a):

a) Las corrientes funcionan como paradigmas. En sí mismas no son teorías, pero, una vez que el investigador se compromete con una de ellas, la corriente constituye el marco de interpretación desde el que se construyen las teorías acerca de la función pedagógica, el discurso pedagógico y la intervención. En tanto que patrones de interpretación, las corrientes configuran la mentalidad pedagógica de sus partidarios y esta mentalidad funciona, bien como presupuesto de la investigación, bien como supuesto. En el contexto de descubrimiento de la investigación funciona como presupuesto; la mentalidad pedagógica de la corriente es, más bien, una anticipación de lo que se espera conseguir, y se centra la observación en aquello que tiene sentido desde la mentalidad específica. En el contexto de justificación de la investigación funciona como supuesto; la mentalidad pedagógica es aquello que no se explicita en la investigación y, sin embargo, de ello depende el sentido de lo que afirmamos acerca de la educación. Precisamente por eso cada corriente redefine el ámbito del conocimiento de la educación, crea nuevos valores o reformula los que ya existían.

b) A cada corriente, en tanto que instrumento útil en la investigación, se le exige rigor lógico (pertinence) y significatividad (significativity, relevance, significance, significant). El rigor lógico se define como existencia de unas características defendidas con exclusividad en cada corriente y que, al mismo tiempo, determinan un modo distinto de entender la educación como objeto de conocimiento. El rigor lógico quiere decir, por tanto, que la inclusión de una obra en una corriente se hace siempre y cuando la obra defiende y reproduce la concepción de la educación como objeto de conocimiento estipulada por esa corriente. Lo importante, para la inclusión de una obra en una corriente, no es el momento en que se escribe, sino la adecuación de su concepción del conocimiento de la educación a la estipulada para la corriente. Por su parte, la significatividad es una consecuencia del rigor lógico, y quiere decir, que, además de clasificar una obra o un pensamiento dentro de una corriente, tenemos que saber el valor de ese pensamiento o de esa obra en la corriente. La significatividad se define como la capacidad que tiene la representación del conocimiento de la educación, resultante del modelo, de ordenar el conocimiento de la educación que se ha producido en el tiempo. La significatividad del modelo posibilita las siguientes cosas (Touriñán, 1987c):

- Identificar la concepción del conocimiento de la educación que subyace en una obra concreta. El hecho de incluirla en una corriente exige que defienda una concepción de la educación como objeto de conocimiento distinta a la que defendería, si estuviera incluida en otra corriente.

- Distinguir evolución basada en la productividad del supuesto (producción desde una concepción específica de la educación como objeto de conocimiento crecimiento simple-) y la evolución basada en cambio de supuesto (elaboración de distinta concepción de la educación como objeto de conocimiento -crecimiento por innovación-).

- Ajustarse a los acontecimientos ocurridos realmente en el desarrollo del conocimiento de la educación; lo cual quiere decir que el modelo de crecimiento 
por sí mismo no debe dar lugar a la desconsideración de obras de Pedagogía que no se ajusten a la tendencia preponderante en el conocimiento de la educación en una época determinada.

c) Cada corriente tiene un techo: su respuesta específica a los criterios discriminantes. Precisamente por eso puede decirse que todo lo que afecta al tema de estudio (la educación) y no contradice la respuesta a los criterios, cabe dentro de la corriente. Por esta razón las corrientes no se definen, ni por el método, ni por la concepción de la ciencia que apoyan más frecuentemente, ni por la concepción filosófica de la vida que tengan sus partidarios. Lo que define una corriente no es el método, porque en la corriente caben todos los métodos compatibles con el techo establecido. Tampoco define la corriente la distinta concepción científica, porque, respecto a la consideración de la educación como objeto de conocimiento, esa concepción es algo externo. En efecto, nuestra consideración de la educación como objeto de conocimiento no varía porque defendamos una u otra concepción de la ciencia, ya que, dentro de esa diversa concepción científica, aceptamos que consideramos la educación como objeto de tratamiento científico. Por la misma razón podemos decir que diferentes concepciones de vida no son diferentes concepciones de la educación como objeto de conocimiento. Lo que varía en cada caso son los fines de la educación que hay que defender, según cuál sea la concepción de la vida, humanista, personalista, católica, etc., pero todas esas concepciones son asumibles desde una misma concepción pedagógica: podemos concebir la función pedagógica como una mera práctica experiencial, aunque los fines que hay que lograr varíen según la concepción filosófica que defendamos. Por consiguiente, cada corriente tiene un techo demarcado por las respuestas a cada uno de los criterios discriminantes, y, así las cosas, lo que define la corriente es la consideración de la educación como objeto de conocimiento que se hace desde la corriente.

d) Por el modo de responder a los criterios discriminantes cada corriente tiene un modo distinto de entender el conocimiento de la educación. Cada modo de entender el conocimiento de la educación ha generado un conjunto de conocimientos acerca de la educación en absoluto despreciables. Las tres corrientes son modos legítimos de abordar la educación. Las aportaciones de cada corriente son la base de su fuerza dentro del gremio de los profesionales de la educación. Según la mentalidad pedagógica configurada, se establece la sustantividad del discurso pedagógico, la intervención y la función pedagógica. En este sentido, criticar una corriente no es sinónimo de absoluto abandono de lo que consideraba valioso, como conocimiento de la educación, la corriente criticada. Se trata, más bien, de reconocer que, al redefinir el marco de interpretación, se crean nuevos valores o se reformulan los que ya existían. El problema así planteado obliga a distinguir, de acuerdo con el techo de cada corriente, la fecundidad de una hipótesis (en este caso, corriente), por una parte, y las vías de investigación que se paralizan o dificultan desde la hipótesis, por otra. La crítica no es la fecundidad, sino al supuesto mismo de cada modo de considerar el conocimiento de la educación. La cuestión de base no es la productividad, sino la pertinencia de limitar, en perspectiva metodológica, la significación del conocimiento de la educación a la capacidad de resolución de problemas que se le atribuyen al conocimiento de la educación en cada corriente. 


\section{CONOCIMIENTO DE LA EDUCACIÓN Y CONOCIMIENTO PEDAGÓGICO}

Después de estos pasos, parece evidente que preguntarse qué conocimiento de la educación se necesita, reclama una respuesta amplia que no quede restringida al conocimiento de la educación que proporcione una de las corrientes. Según el tipo de problemas que estemos planteando, necesitaremos conocimiento autónomo, subalternado o marginal. A veces necesitaremos ciencia de la educación (necesitaremos teorías sustantivas de la educación para explicar y comprender la educación en conceptos propios, haciendo reglas y normas derivadas del proceso); a veces necesitaremos estudios científicos de la educación, teorías prácticas y teorías interpretativas (reglas para fines dados y orientaciones de la acción hacia determinados efectos que justifica la teoría interpretativa; orientar la intervención hacia fines socialmente prescritos o para comprender la intervención educativa en términos validados por otras disciplinas consolidadas, como la Psicología, la Sociología, etcétera); y por último, necesitaremos estudios filosóficos de la educación, cuando queramos hacer fenomenología de un fin en sí, estudiar la lógica interna del fin dentro del sistema conceptual de Educación o conocer las consecuencias que se derivan para la educación de una determinada concepción de vida. necesitaremos teorías filosóficas (en plural) de la educación, que se centran en conocer las consecuencias que se derivan para la educación de una determinada concepción de vida y, a veces, necesitaremos teoría filosófica (en singular) de la educación que se centra en hacer análisis fenomenológico, dialéctico, crítico-hermenéutico o lingüístico de un fin en sí, estudiar la lógica interna del fin dentro del sistema conceptual de "educación”, etcétera (Touriñán, 2019b y 2020c).

El conocimiento de la educación procede de muy diversas formas de conocimiento (ver Touriñán, 1987a, 1987b y 1989) y genera muy diversas disciplinas. Hay disciplinas derivadas de las filosofías, hay disciplinas derivadas de las teorías interpretativas, hay disciplinas derivadas de teorías prácticas y hay disciplinas derivadas de teorías sustantivas. La estructura conceptual del conocimiento de la educación en cada una de ellas es distinta, como podemos ver en los siguientes epígrafes.

\subsection{Teorías Filosóficas de la educación}

Las teorías filosóficas de la educación resuelven la educación deductivamente, desde las concepciones del mundo y de la vida. Su objetivo es la formulación explícita de los intereses de vida y la propuesta del modo de armonizar esos intereses. Su propuesta definitiva es la de establecer con qué fin se lleva a cabo la educación, o, dicho de otro modo, su propuesta es el estudio normativo de los fines de vida en los que deben formarse los hombres (Touriñán, 2017a; Fullat, 1979; Bowen y Hobson, 1979; Brubacher, 1962).

La estructura conceptual de las teorías filosóficas de la educación es deductiva, desde las concepciones del mundo y de la vida (Cuadro 3). 


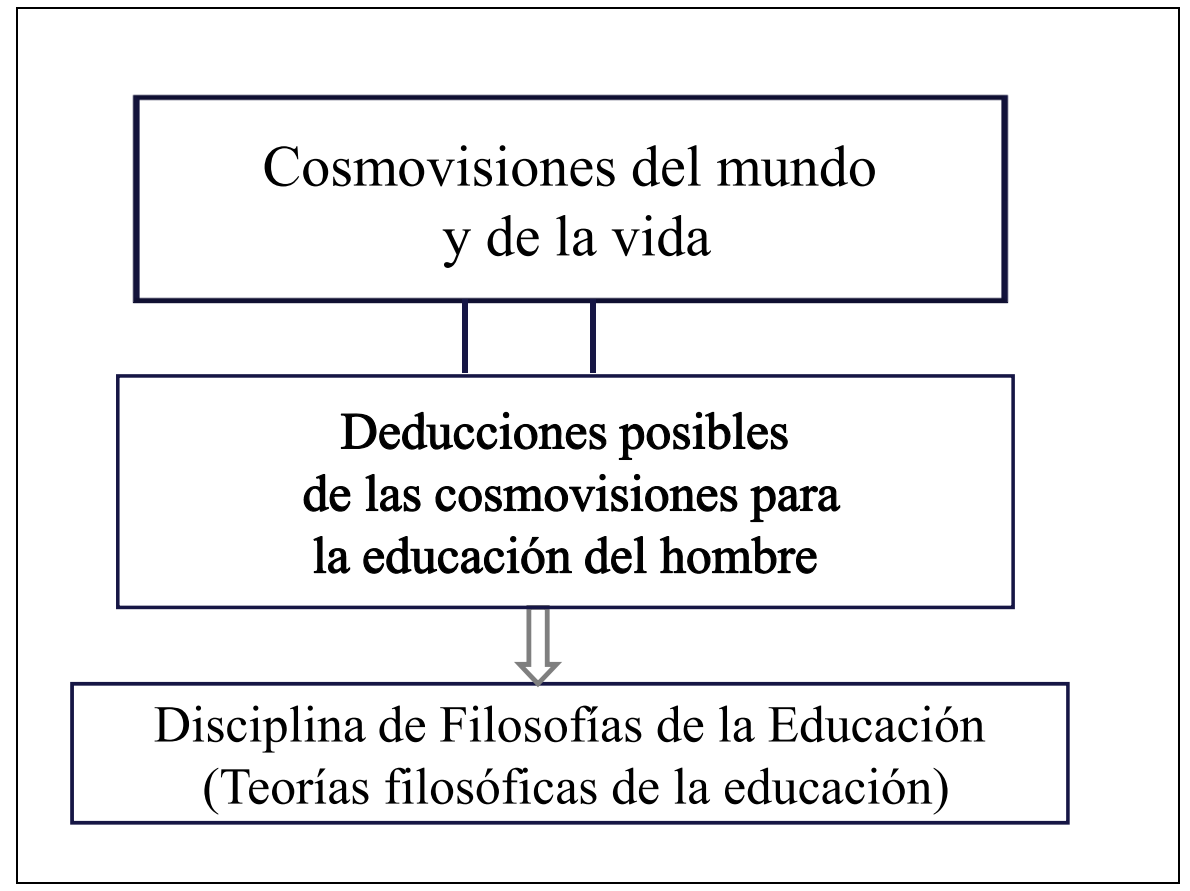

Cuadro 3. Estructura de la Teoría de la Educación como Teorías Filosóficas acerca de la educación. Fuente: Touriñán, 2016, p. 879

Las teorías filosóficas de la educación aportan conocimiento acerca de las consecuencias que se derivarían de cada cosmovisión que se postule como "a priori" de la intervención. Son estudios que deben formar parte de la cultura de los profesionales de la Pedagogía (Davis, 1987). Pero la capacidad para generar principios de intervención pedagógica y para explicar y prescribir reglas de intervención es realmente escasa porque en esta corriente (Touriñán, 1987b):

- La relación entre la teoría y la intervención es extrínseca

- Se centran las reflexiones en los fines de vida deseables y no en las metas pedagógicas y reglas de la intervención

- Entienden el problema de la educación como justificación moral de conductas singulares y no como explicación científica de acontecimientos pedagógicos intencionales

- La educación no es vista como un objeto de estudio propio, sino como una consecuencia de otras preocupaciones intelectuales: las cosmovisiones.

Adviértase que las afirmaciones anteriores no invalidan las teorías filosóficas de la educación. Antes bien, ponen de manifiesto su limitación, en la misma medida que se pretenda utilizarlas para algo que no es su cometido: explicar el modo de intervenir (Suchodolsky, 1979; García Aretio, 1989; García Aretio, Ruiz Corbella y García Blanco, 2009; Bowen y Hobson, 1979; Carr, 2006; Capitán, 1979; Fermoso, 1976; Smeyers, 2010). A veces, haremos teorías filosóficas (en plural) de la educación, que se centran en conocer las consecuencias que se derivan para la educación de una determinada concepción de vida (así se hacen las filosofías de la educación o teorías filosóficas, en plural, de la educación) y, a veces, haremos teoría filosófica (en singular) de la educación que se centra en hacer análisis fenomenológico, dialéctico, críticohermenéutico o lingüístico de un fin en sí, estudiar la lógica interna del fin dentro del 
sistema conceptual de “educación”, etcétera (así se hace la filosofía de la educación o teoría filosófica, en singular, de la educación). La filosofía se convierte, en este caso, en filosofía aplicada a la educación o, dicho de otro modo, en teoría interpretativa de la educación (Touriñán, 2019b y 2020c).

\subsection{Teorías Interpretativas de la educación}

Las teorías interpretativas establecen vinculaciones entre condiciones y efectos de un acontecimiento educativo en términos de las disciplinas generadoras, pues en las teorías interpretativas la educación carece de sistema conceptual propio y de estructura teórica propia, consolidada.

Las disciplinas generadoras son las que, bajo criterio ontológico y epistemológico, generan conceptos propios de la parcela de realidad que estudian con autonomía funcional (forma de conocimiento + ámbito de realidad para conocer + autonomía funcional metodológica). Una disciplina que tiene conceptos propios puede aplicarse a la interpretación de otros ámbitos de realidad siempre que esos ámbitos se ajusten a esos conceptos en alguna medida. De este modo la disciplina generadora se convierte en teoría interpretativa del ámbito en el que se aplica, porque lo interpreta desde los conceptos de la disciplina generadora.

Existen preocupaciones y estudios acerca de la educación que se resuelven en términos de disciplinas generadoras (con conceptos aplicables a educación y la interpretan desde esos conceptos), tales como la Psicología, la Sociología, la Biología, etc. La educación puede ser interpretada en términos de motivación y comportamiento, en términos de salud y vida, en términos de relaciones sociales, etc. En estos casos, la educación es un ámbito de realidad para estudiar que se resuelve en teorías interpretativas o investigaciones aplicadas, hablamos en este caso de psicología de la educación, biología de la educación, sociología de la educación, etc.

La estructura conceptual de las teorías interpretativas se ajusta al siguiente esquema común para las disciplinas generadoras o interpretativas, biología, antropología, psicología, historia, sociología, economía, etc. (Cuadro 4).

A los efectos de este discurso hacemos sinónimos investigación aplicada y teoría interpretativa. En la literatura científica, el término "aplicada" se entiende en dos acepciones (Touriñán, 2016):

a) Como aplicación de una ciencia a otro conocimiento (este es el sentido estricto de la teoría interpretativa).

b) Como aplicación de una ciencia a problemas prácticos o a objetivos sociales (es el sentido estricto de las teorías prácticas).

Ambos sentidos de investigación aplicada han venido contraponiéndose al concepto de investigación tecnológica, dando lugar así a tres categorías: investigación básica, investigación aplicada e investigación tecnológica.

En nuestra opinión el sentido primero (a) de investigación aplicada es epistemológicamente similar a la estructura de la investigación básica (patrones de explicación, vinculando por medio de teorías condiciones y acontecimientos).

El sentido segundo (b) de investigación aplicada tiene epistemológicamente, una estructura similar a la de la investigación tecnológica (transforma una realidad encadenando, por medio de las teorías, un proceso de reglas que permiten lograr las metas construyendo las condiciones más adecuadas). 


\section{Forma de conocimiento científico-tecnológico}

Ámbitos de la realidad, resueltos disciplinarmente con autonomía funcional y conceptos con significación intrínseca en sus términos

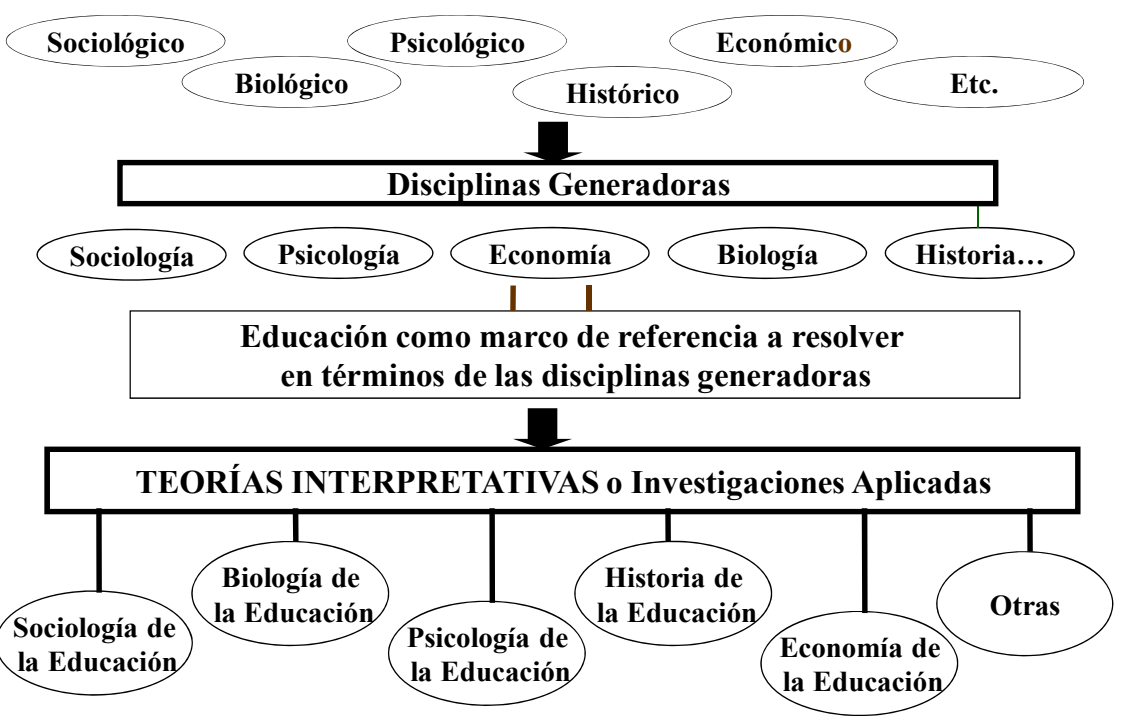

Cuadro 4. Estructura de Teoría de la Educación como teoría interpretativa. Fuente: Touriñán, 2016 , p. 882

Nuestra posición, por tanto, distingue dos grandes categorías epistemológicas: la investigación científica y la investigación tecnológica. Cada una de ellas es susceptible, a su vez, de dos estructuras:

- Investigación científica (básica y aplicada o teorías interpretativas).

- Investigación tecnológica (teorías prácticas y tecnologías sustantivas).

Ambas categorías tienen un papel específico en la práctica, que se entiende aquí como la puesta en acción de la secuencia de intervención concreta en cada caso.

Con todo, debe quedar bien claro que la mayor semejanza epistemológica a nivel de estructura, entre la teoría práctica y la investigación tecnológica, frente a la teoría interpretativa, no da pie a obviar las diferencias entre teorías prácticas y tecnologías sustantivas. Las teorías prácticas, dado que la validez de las metas no se deriva del propio proceso, sino del carácter social y moral de estas, conviene encuadrarlas también con propiedad en el ámbito de la racionalidad práxica. Las teorías prácticas forman parte, por la validación de los medios, de la racionalidad científico-tecnológica, y por la validación de las metas, forman parte de la racionalidad práxica.

\subsection{Teorías Prácticas de la educación}

La estructura conceptual básica de una teoría práctica, que reproducimos a continuación, responde a una concepción por medio de la que las Teorías prácticas se definen como construcciones racionales que dirigen la acción combinando metasexpectativas, social y moralmente sancionadas como metas educativas, y medios validados por teorías interpretativas. Las teorías prácticas no son cuestión exclusiva de 
la educación, sino de cualquier otro campo en el que existan expectativas sociales (Carr y Kemmis, 1988; Novak, 1977; García Carrasco y García del Dujo, 2001; García Carrasco, 2016; SI(e)TE, 2018). En la educación existen expectativas sociales y parece innegable, por tanto, que es un campo adecuado para el desarrollo de teorías prácticas (Cuadro 5).

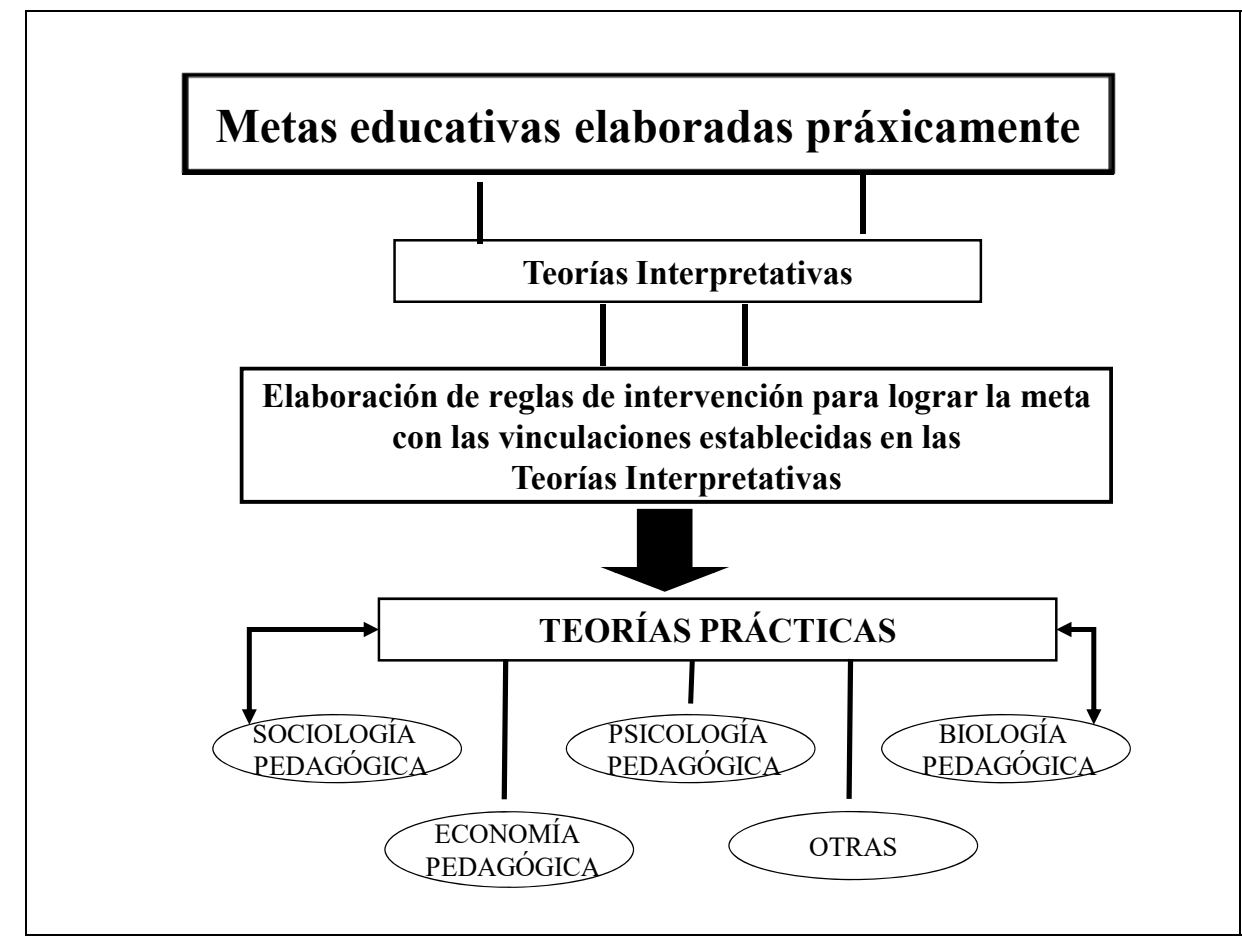

Cuadro 5. Estructura de la Teoría de la Educación como teoría práctica. Fuente: Touriñán, 2016, p. 884

Para clarificar esta concepción de la teoría práctica, es oportuno seguir una estrategia comparada. En efecto, la Biología es una disciplina científica con estructura teórica consolidada; dispone de teorías sustantivas y tecnologías específicas, elaboradas en conceptos propios de la Biología. Desde conceptos propios de la Biología, sus teorías sustantivas establecen vinculaciones entre condiciones y efectos y legitiman cambios de estado, es decir, establecen metas u objetivos intrínsecos de la Biología; por su parte, sus tecnologías específicas prescriben reglas para alcanzar esos objetivos intrínsecos con las vinculaciones establecidas en sus teorías sustantivas. Pero, además, si nos preguntamos cómo contribuir a la salud de la sociedad con la Biología, estamos planteando una cuestión de teoría práctica. La Biología es un estudio autónomo que tiene sus objetivos intrínsecos; pero, también, contribuye a solucionar objetivos extrínsecos desde teorías prácticas en la misma medida que aquellos puedan interpretarse en términos biológicos. Respecto de la educación podemos actuar analógicamente y entenderla como una meta social que se resuelve en términos de la biología; construimos, así, en primer lugar, la biología de la educación como teoría interpretativa y, a continuación, generamos la biología pedagógica o teoría práctica de la educación desde el patrón subalternado a la Biología. 


\subsection{Teorías Sustantivas de la Educación}

En la corriente autónoma del conocimiento de la educación, las disciplinas científicas se entienden como disciplinas generadoras. Las disciplinas generadoras son las que, bajo criterio ontológico y epistemológico, generan conceptos propios de la parcela de realidad que estudian con autonomía funcional (Forma de conocimiento + ámbito de realidad para conocer + autonomía funcional metodológica). Una disciplina que tiene conceptos propios puede aplicarse a la interpretación de otros ámbitos de realidad siempre que esos ámbitos se ajusten a esos conceptos en alguna medida. De este modo, la disciplina generadora se convierte en teoría interpretativa del ámbito en el que se aplica. Desde los conceptos de la disciplina generadora interpretamos el ámbito al que se aplica. Desde esta perspectiva de aproximación, los conceptos propios de la disciplina Pedagogía pueden utilizarse para interpretar ámbitos en los que la educación es el contexto de interpretación y así la Pedagogía es generadora de disciplinas aplicadas (pedagogía familiar, pedagogía laboral, pedagogía social, etcétera).

Dentro de la Pedagogía como disciplina autónoma se dan los niveles de análisis epistemológico (teoría, tecnología e investigación activa o práctica) para resolver el conocimiento de la educación en conceptos con significado intrínseco al ámbito de estudio. La acepción "teoría sustantiva", se corresponde con uno de los tres niveles de análisis (el nivel de análisis teórico, la teoría sustantiva) que se identifican en la Pedagogía como disciplina autónoma del conocimiento de la educación (Touriñán, 2016; Touriñán y Sáez, 2015, Touriñán y Longueira, 2016; Rodríguez, 2006; Touriñán y Rodríguez, 1993; Touriñán, 2020c).

La estructura conceptual básica de una teoría sustantiva se ajusta al esquema del Cuadro 6.

Desde este planteamiento es legítimo decir que la Pedagogía como ciencia de la educación es teoría, tecnología y práctica de la Educación, o sea, que además de existir, como ya hemos visto, investigaciones aplicadas de la educación y teorías prácticas de la educación, en la Pedagogía hay investigación básica y tecnológica (Castillejo y Colom, 1987).

La existencia de disciplinas aplicadas al lado de disciplinas científicas generadoras ha dado lugar a la diferenciación entre disciplina general y aplicada. Es obvio que bajo esa diferencia se han construido diversas disciplinas aplicadas o teorías interpretativas en otros ámbitos científicos, porque tienen conceptos propios que pueden aplicarse a la interpretación de otros ámbitos de realidad siempre que esos ámbitos se ajusten a esos conceptos en alguna medida. Así, se habla de sociología general y aplicada, de economía general y aplicada, de biología general y aplicada; se habla de Psicología, de Medicina, de Antropología, de Pedagogía y de las demás disciplinas científicas como disciplinas generadoras. Pero, en cada caso concreto de existencia de disciplina general y aplicada, estamos asumiendo, en palabras de González Álvarez, que las disciplinas aplicadas especializan la tarea, no la disciplina (González Álvarez, 1977). 


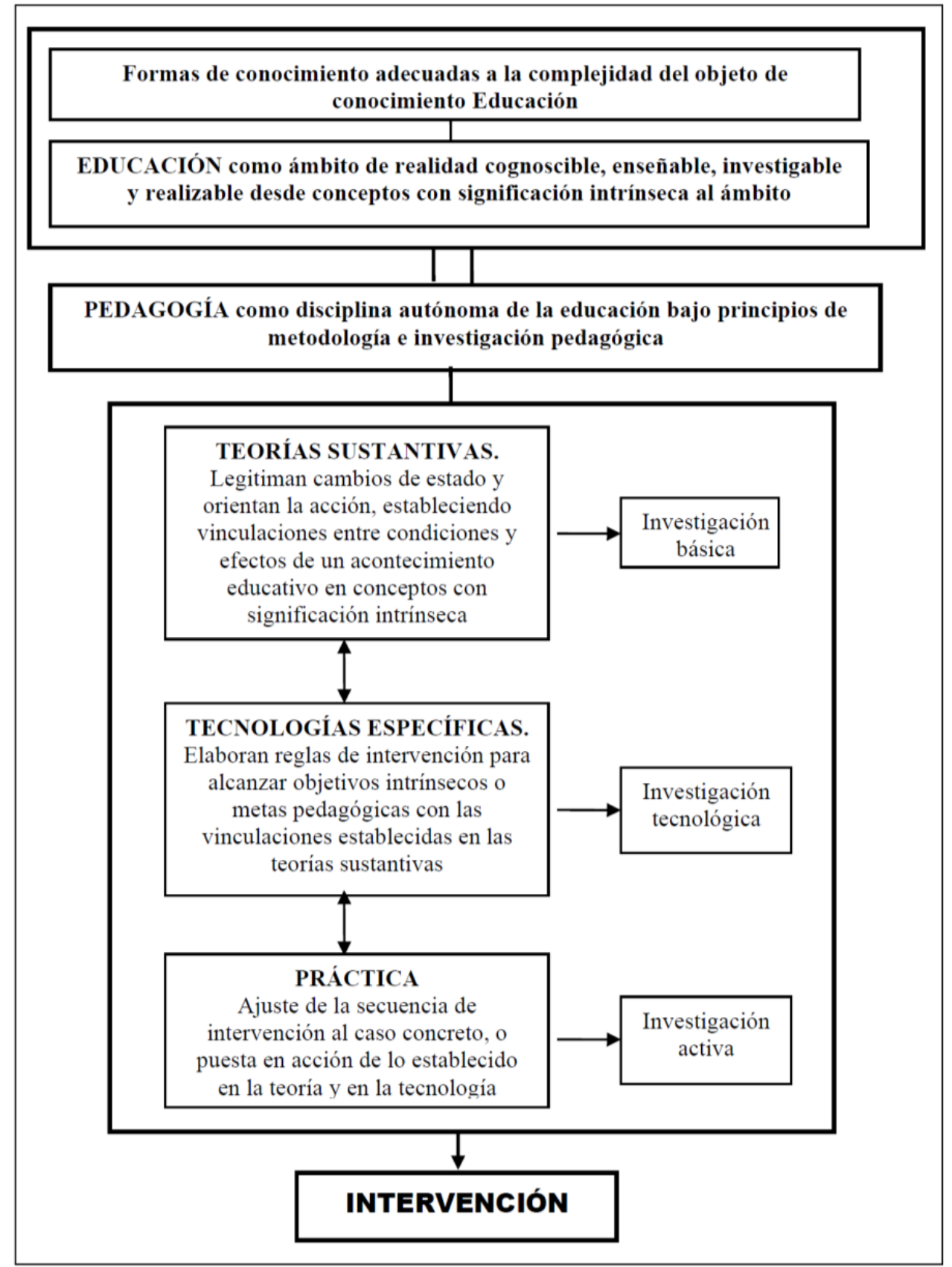

Cuadro 6. Pedagogía como disciplina con autonomía funcional. Fuente: Touriñán, 2016, p. 887

La psicología de la educación, la psicología del trabajo, la sociología de la educación, la pedagogía laboral, la pedagogía familiar, la pedagogía social, etcétera, especializan la tarea, no la disciplina; son y aplican Sociología, Psicología, Pedagogía, etcétera, a ámbitos distintos, que son susceptibles de interpretación en términos de relación social, comportamiento y motivación, de intervención pedagógica, etcétera, según cuál sea la disciplina generadora de la interpretación.

En este sentido, se dice que la pedagogía laboral, la pedagogía familiar y otras disciplinas aplicadas de la Pedagogía especializan la tarea, no la disciplina Pedagogía, que sigue siendo la misma que aplica los conceptos creados por la Pedagogía a la interpretación de cada uno de esos ámbitos en los que se aplican. 
En el caso de las investigaciones aplicadas, la prueba depende de los conceptos propios de la disciplina generadora (Psicología, Biología, Sociología, Pedagogía, Antropología, etc.), pues son esos conceptos los que interpretan el ámbito aplicado.

Pero en el caso de disciplinas científicas con autonomía funcional, cada disciplina depende de sus propias pruebas. Desde la perspectiva de la Pedagogía como disciplina con autonomía funcional que genera conceptos propios con significación intrínseca al ámbito de estudio, respecto de la educación, puede decirse que pedagógicamente probado no es lo mismo que psicológicamente probado, porque los criterios de significado de educación en Pedagogía no son criterios de Psicología, ni el significado de los conceptos de educación se reducen a términos de la psicología, aunque estos puedan utilizarse para interpretar la educación. Y esto se predica también de las disciplinas académicas sustantivas creadas por parcelación de cada disciplina generadora.

Por consiguiente, cuando hablamos de disciplinas académicas sustantivas, por ejemplo, psicología general, psicología evolutiva, psicología comparada (todas ellas disciplinas derivadas de la parcelación, con criterio ontológico y epistemológico, de la disciplina generadora de Psicología, no de la aplicación de la psicología a otro ámbito de realidad cognoscible e interpretable en conceptos propios de la psicología), la cuestión no es que se especialice la tarea, aplicándose a otro ámbito o conjunto de problemas la disciplina generadora (hacer, por ejemplo, psicología de la educación, del arte, del trabajo, etc.), sino que, dentro de la Psicología, se especializa la disciplina misma. Las disciplinas aplicadas especializan la tarea, porque la tarea es siempre interpretar otro ámbito en términos de Psicología, Sociología etc. (según cuál sea la disciplina matriz), pero en las disciplinas sustantivas se especializa la disciplina científica misma, porque cada disciplina sustantiva genera sus conceptos distintivos y modos de prueba sobre una parcela de la disciplina científica matriz (Psicología, Sociología, Pedagogía u otras).

Cada disciplina sustantiva tiene sus problemas y sus métodos de trabajo, según cuál sea su objeto de estudio o ámbito de conocimiento dentro de la parcela que le corresponde de la disciplina científica matriz. Y esto es lo que hay que tener presente cuando se une el calificativo "general" a una disciplina sustantiva. En el caso de Pedagogía, cuando hablamos de disciplinas sustantivas, como la pedagogía general, la didáctica o la pedagogía comparada, queremos decir que todas son Pedagogía; todas tienen problemas teóricos, tecnológicos y prácticos de su ámbito; todas son disciplinas sustantivas, pero la Pedagogía General no resuelve el problema de la Didáctica o el problema de la Pedagogía Comparada, porque, dentro de "educación", "intervención pedagógica", "enseñanza" y "sistema educativo" son tres conceptos con problemas teóricos, tecnológicos y prácticos específicos y porque las disciplinas sustantivas se diferencian por la parcela del ámbito de conocimiento que les incumbe (en este caso, y tomando como referencia la educación como objeto de estudio de la Pedagogía, sus parcelas singulares son la intervención pedagógica, la enseñanza y el sistema educativo, respectivamente) y elaboran sus conceptos específicos, sus contenidos propios y sus pruebas desde los análisis teóricos, tecnológicos y prácticos de la parcela de conocimiento de la educación que le compete a cada una de ellas.

Cada una de estas disciplinas sustantivas puede aplicarse (igual que la disciplina científica de la que nacen por parcelación del ámbito de conocimiento), a otros ámbitos, 
especializando la tarea, y precisamente por eso podemos hablar con propiedad de disciplinas aplicadas como pedagogía del trabajo, pedagogía social, pedagogía escolar, y de didácticas específicas o aplicadas como la didáctica de las ciencias sociales, y la didáctica de las matemáticas, por ejemplo.

Se sigue, por tanto, que, definir la disciplina sustantiva, no es un problema de hacer pedagogías aplicadas o de aplicar la disciplina a otros ámbitos interpretables desde aquellas ni de hacer teorías sustantivas, sino más bien un problema previo, de parcelación de la disciplina matriz, Pedagogía. Existen pedagogías aplicadas (Pedagogía del trabajo, de la familia, de la educación general, de la educación profesional, de la educación de adultos, de lo social, u otras) y existen didácticas aplicadas o didácticas específicas, que especializan la tarea. Las disciplinas aplicadas van a existir siempre que avance la posibilidad de aplicación de la disciplina matriz. El problema de la disciplina académica sustantiva es de delimitación junto a otras disciplinas sustantivas del mismo rango dentro de la disciplina matriz y que tienen todas ellas, por tanto, su ámbito de conocimiento y su conocimiento del ámbito, definidos ontológica y epistemológicamente en relación con la parcela que les corresponde dentro de la disciplina científica matriz. Cada disciplina sustantiva hace teoría sustantiva, tecnología específica y práctica de su parcela individualizada de conocimiento.

La Pedagogía como ciencia, los estudios interdisciplinares de la educación, o estudios subalternados, y los estudios filosóficos de la educación no se confunden, aunque todos son conocimiento de la educación y todos forman parte en distinta medida de los estudios propios de la Pedagogía como carrera.

Los distintos modos de entender el conocimiento de la educación han generado una diversidad necesaria de conocimientos teóricos de la educación, según el tipo de problemas que se estén analizando. A veces necesitaremos teorías sustantivas de la educación (para explicar y comprender la educación en conceptos propios); a veces necesitaremos teorías prácticas y teorías interpretativas (para orientar la intervención hacia fines socialmente prescritos o para comprender la intervención educativa en términos validados por otras disciplinas consolidadas, como la Psicología, la Sociología, etc.); y, a veces, necesitaremos teorías filosóficas (en plural) de la educación, que se centran en conocer las consecuencias que se derivan para la educación de una determinada concepción de vida (así se hacen las filosofías de la educación o teorías filosóficas, en plural, de la educación) y, a veces, necesitaremos teoría filosófica (en singular) de la educación que se centra en hacer análisis fenomenológico, dialéctico, crítico-hermenéutico o lingüístico de un fin en sí, estudiar la lógica interna del fin dentro del sistema conceptual de "educación", etc. (así se hace la filosofía de la educación o teoría filosófica, en singular, de la educación).

Si esto es así, igual que podemos afirmar que no todo conocimiento de la educación es Pedagogía en el sentido de pedagogía como disciplina científica con autonomía funcional, también podemos afirmar, sin contradicción, que de todo conocimiento de la educación se deriva un cierto conocimiento pedagógico, porque el conocimiento pedagógico nace del estudio de la intervención, es decir, del estudio de la relación teoría-práctica; y, en cada corriente, por su modo de entender el conocimiento de la educación, se genera un conocimiento distinto de la intervención (en unos casos el conocimiento es experiencial, en otros es de teoría práctica y en otros de tecnología específica) (Touriñán y Sáez, 2015). 
El conocimiento de la educación tiene su manifestación más genuina en el conocimiento pedagógico, que es el que determina la acción profesional en cada función pedagógica. El conocimiento pedagógico nace del estudio de la intervención, y dado que de todo conocimiento de la educación se deriva a través de la relación teoríapráctica una cierta consideración o recomendación para la intervención, podemos decir que de todo conocimiento de la educación se deriva un cierto conocimiento pedagógico. Por la misma razón podemos decir que toda intervención educativa es, en cierta medida, una intervención pedagógica, porque en toda intervención educativa hay una componente de conocimiento pedagógico, que nace del estudio de la relación teoríapráctica y que no tiene siempre el mismo nivel de elaboración técnica en su manifestación. Esto es así y podemos decir, por tanto, que en un determinado tipo de intervención educativa hay un conocimiento pedagógico experiencial, en otro, hay conocimiento pedagógico de teoría práctica y, en otro, hay conocimiento pedagógico de tecnología específica (Cuadro 7).

\begin{tabular}{|c|c|c|c|}
\hline $\begin{array}{c}\text { Criterios } \\
\text { discriminantes }\end{array}$ & $\begin{array}{l}\text { Corriente marginal } \\
\text { Estudios filosóficos } \\
\text { cosmovisionarios }\end{array}$ & $\begin{array}{c}\text { Corriente de } \\
\text { subalternación } \\
\text { Estudios interpretativos } \\
\text { interdisciplinares }\end{array}$ & $\begin{array}{c}\text { Corriente autónoma } \\
\text { Estudios de Pedagogía como } \\
\text { disciplina con autonomía } \\
\text { funcional }\end{array}$ \\
\hline $\begin{array}{c}\text { Tipo de } \\
\text { conocimiento a } \\
\text { obtener para } \\
\text { saber } \\
\text { educación. }\end{array}$ & $\begin{array}{c}\text { Fines de vida y } \\
\text { justificación de fines. } \\
\text { Consecuencias que se } \\
\text { deducen para la } \\
\text { educación desde } \\
\text { Teorias filosóficas } \\
\text { cosmovisionarias }\end{array}$ & $\begin{array}{l}\text { Medios, para fines } \\
\text { dados, vinculando } \\
\text { condiciones y efectos a } \\
\text { un acontecimiento } \\
\text { desde } \\
\text { Teorias interpretativas } \\
\text { o Investigaciones } \\
\text { aplicadas }\end{array}$ & $\begin{array}{c}\text { Fines y medios derivados del } \\
\text { proceso de intervención } \\
\text { pedagógica, vinculados a } \\
\text { Teorías sustantivas }\end{array}$ \\
\hline $\begin{array}{l}\text { Modo de } \\
\text { resolver el } \\
\text { acto de } \\
\text { intervención }\end{array}$ & $\begin{array}{l}\text { Utilizando la } \\
\text { experiencia del } \\
\text { acto de } \\
\text { intervención } \\
\text { concreto }\end{array}$ & $\begin{array}{l}\text { Utilizando reglas y } \\
\text { normas derivadas de } \\
\text { Teorias Prácticas y } \\
\text { aplicaciones técnicas }\end{array}$ & $\begin{array}{c}\text { Construyendo reglas y } \\
\text { normas vinculadas } \\
\text { desde } \\
\text { Tecnologias } \\
\text { especificas }\end{array}$ \\
\hline $\begin{array}{l}\text { De dónde } \\
\text { proviene el } \\
\text { componente de } \\
\text { conocimiento } \\
\text { pedagógico en } \\
\text { cada } \\
\text { intervención }\end{array}$ & $\begin{array}{l}\text { De la capacidad de } \\
\text { resolución de } \\
\text { problemas para la } \\
\text { intervención con la } \\
\text { relación teoria- } \\
\text { práctica en la } \\
\text { corriente marginal. }\end{array}$ & $\begin{array}{l}\text { De la capacidad de } \\
\text { resolución de } \\
\text { problemas para la } \\
\text { intervención con la } \\
\text { relación teoría-práctica } \\
\text { en la corriente } \\
\text { subalternada }\end{array}$ & $\begin{array}{l}\text { De la capacidad de } \\
\text { resolución de } \\
\text { problemas para la } \\
\text { intervención con la } \\
\text { relación teoría-práctica } \\
\text { en la corriente } \\
\text { autónoma }\end{array}$ \\
\hline
\end{tabular}

Cuadro 7. Derivación del conocimiento pedagógico según las corrientes. Fuente: Touriñán, 2016, p. 112

\section{INTERVENCIÓN PEDAGÓGICA Y SIGNIFICACIÓN DEL CONOCIMIENTO DE LA EDUCACIÓN EN CADA CORRIENTE DESDE LA RELACIÓN TEORÍA PRÁCTICA}

La significación del conocimiento de la educación no debe ser confundida con la significatividad o con el significado de educación o con el concepto de conocimiento de la educación. La significación se define, tal como hemos dicho en la Introducción y en 
los epígrafes 4 y 5 , como la capacidad de resolución de problemas que se le atribuye al conocimiento de la educación en cada corriente. La significación es un problema epistemológico de la metodología general de investigación (Touriñán, 2016).

La significación (signification or meaningness or sense of), como principio de metodología de investigación, se asocia a la validez del conocimiento de la educación y se define como la capacidad de resolución de problemas que se le atribuye al conocimiento de la educación en cada corriente desde la perspectiva de la relación teoría-practica para la actividad educativa. A cada corriente, en tanto que instrumento útil en la investigación, se le exige rigor lógico (pertinence) y significatividad (significativity, relevance, significance, significant). Y, además, al conocimiento de la educación se le exige, desde la perspectiva de la metodología general de investigación, significación.

La significación, como principio de metodología de investigación, determina la validez (validity) del conocimiento de la educación. La significación como principio de investigación apunta a la validez y a la fiabilidad (reliable) del significado, al valor metodológico del significado. El conocimiento de la educación tiene significación, si resuelve problemas de la educación relacionando teoría y práctica: cuanto mejor resuelve los problemas relacionando teoría y práctica, más válido es. Según la significación que tiene, así es de válido y es válido, si sirve para educar y, si no sirve para educar, no tiene significación y no es válido.

La significación quiere decir también que el conocimiento de la educación es fiable (creíble y contrastable, que da seguridad); es decir, lo que dice, está dicho con exactitud y precisión. Desde la perspectiva de la metodología de investigación, la significación es principio de investigación pedagógica vinculado al conocimiento de la educación que siempre debe resolver problemas de intervención con validez y fiabilidad.

Cada mentalidad pedagógica genera, como ya dijimos, un contenido diferente para el discurso, la función y la intervención, que queda recogida, respecto de la relación teoría-práctica, en el cuadro Capacidad de resolución de problemas para la intervención que exponemos y comentamos a continuación, recogiendo la estructura básica de cada corriente (Cuadro 8).

En la mentalidad pedagógica marginal la capacidad de resolución de problemas de intervención que se le atribuye al conocimiento de la educación se limita a la experiencia personal que uno tenga de su acción y a las consecuencias que se deriven para la educación de la cosmovisión que se asume. Desde una perspectiva global, nos parece absolutamente correcto reconocer que bajo la intervención de cualquier técnico subyace una idea genérica de hombre. En el fondo, los estudios pertenecientes a la corriente marginal aportan conocimiento acerca de las consecuencias que se derivarían de cada cosmovisión que se postula como "a priori" de la intervención. Pero su capacidad para generar intervención pedagógica es escasa porque la relación entre la teoría y la práctica es externa en esta corriente. Esta propuesta de conexión externa entre la teoría y la práctica es válida para la teoría filosófica, pero es insuficiente para resolver la intervención pedagógica. La teoría proporciona las finalidades de vida deseables y recomendaciones generales para la actuación; a su vez, la práctica se realizará en la misma medida en que se sepa que el objetivo que se va a lograr es una determinada finalidad de vida deseable. En una mentalidad así, la práctica es independiente de la teoría, en el orden de justificación de la acción, porque la función de la teoría no es explicar el modo de intervenir, sino identificar la meta. A lo sumo, se produce una 
vinculación externa entre la teoría (metas que hay que alcanzar) y la práctica. La práctica se une a la teoría, cuando aquella es exitosa, es decir, es buena práctica, porque permite alcanzar la meta. Pero no se dice, de ningún modo: es una buena práctica, porque la teoría explica lo que hay que hacer.

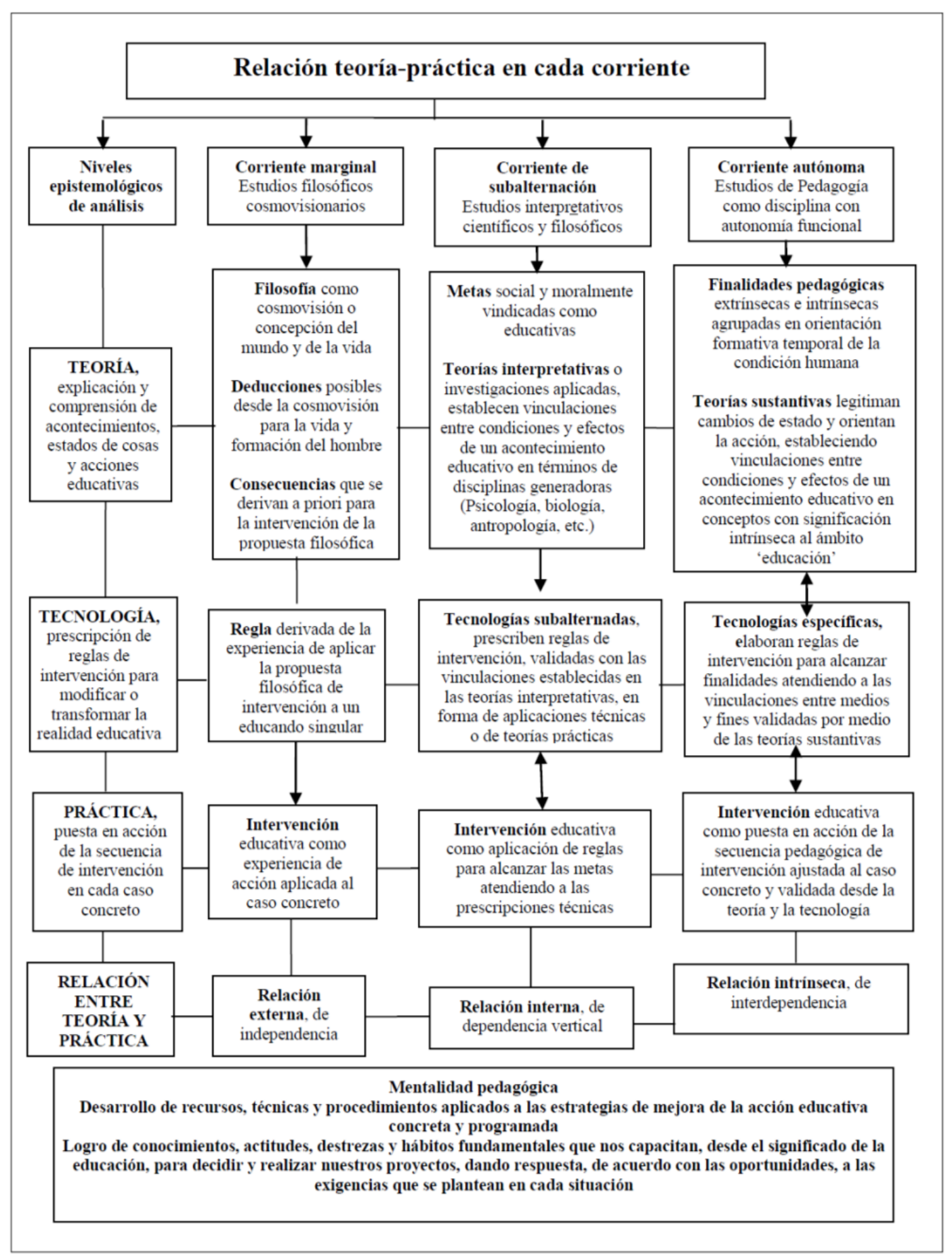

Cuadro 8. Capacidad de resolución de problemas para la intervención. Fuente: Touriñán, 2016, p. 115 
En la mentalidad pedagógica subalternada la capacidad de resolución de problemas de intervención que se le atribuye al conocimiento de la educación es el correspondiente a las Teorías prácticas que se elaboran de forma subalternada con las Teorías interpretativas y las metas socialmente sancionadas como metas de la educación. En esta mentalidad la conexión entre la teoría y la práctica no es externa como en la corriente marginal. Las teorías explican e interpretan vinculaciones que existen entre condiciones y efectos que afectan a un conocimiento educativo en términos de las disciplinas generadoras. La práctica es la puesta en acción de una determinada secuencia de intervención. Entre la teoría y la práctica se instala la tecnología que es el proceso de prescripción de reglas de intervención para alcanzar metas. En este planteamiento la práctica no es independiente de la teoría en el orden de justificación de la acción. La teoría interpretativa, en el contexto de justificación de la acción, rige la práctica, porque la función de la teoría es explicar el modo de intervenir, estableciendo vinculaciones entre condiciones y efectos que constituyen una intervención, una vez que se acepta que el marco teórico interpretativo se adecúa a la meta educativa elaborada práxicamente. Pero la práctica no rige a la teoría en el contexto de justificación de la acción, porque la validez de la teoría interpretativa se ha establecido en su propio ámbito, que es el de la disciplina generadora, y la de la meta educativa se ha establecido práxicamente. La validez de estas reglas está garantizada por la validez de las vinculaciones establecidas en términos de la disciplina generadora y por la eficacia probada de la regla; es decir, por la medida en que las vinculaciones establecidas sirven para alcanzar las metas educativas dadas socialmente o elaboradas práxicamente desde el sistema "educación”. En la mentalidad pedagógica subalternada, si una regla aplicada en una intervención no es eficaz, ello no anula la validez de las vinculaciones establecidas en la disciplina generadora, tan sólo cuestiona su aplicación.

En la mentalidad pedagógica autónoma la capacidad de resolución de problemas de intervención que se le atribuye al conocimiento de la educación es el de elaborar principios y programas de intervención pedagógica desde teorías sustantivas de la educación y tecnologías específicas. En la corriente autónoma, la conexión entre la teoría y la práctica no es externa como en la corriente marginal. Del mismo modo que en la corriente de subalternación, las teorías explican y establecen vinculaciones entre las condiciones y efectos que afectan a un acontecimiento, la práctica es la puesta en acción de una determinada secuencia de intervención, y entre la teoría y la práctica se instala la tecnología que es el proceso de prescripción de reglas de intervención. Ahora bien, el hecho de que sean los mismos conceptos con significación intrínseca a la educación, no sólo los que intepretan las vinculaciones entre condiciones y efectos, sino también los que legitiman las metas pedagógicas, hace que, a diferencia de la corriente de subalternación, la práctica sea interdependiente con la teoría en el orden de justificación de la acción. La teoría sustantiva rige la práctica en el contexto de justificación de la acción, porque la función de la teoría es explicar el modo de intervenir, estableciendo vinculaciones entre condiciones y efectos que afectan a una intervención. Pero, a su vez, la práctica rige a la teoría en el contexto de justificación, porque son los hechos ocurridos en cada intervención los que sirven de elemento de referencia para comprobar en qué medida la teoría da cuenta ajustada de los acontecimientos acaecidos. La validez de la regla es la validez de las vinculaciones establecidas en las teorías sustantivas junto con la eficacia probada de la regla para alcanzar la meta. Pero, dado que las vinculaciones y la meta se establecen en los 
mismos términos, si una regla aplicada a una intervención no es eficaz, puede verse afectada la validez de las vinculaciones establecidas en la teoría sustantiva. En efecto, como las vinculaciones y las metas se establecen en los mismos términos, si, una vez ajustadas las condiciones de aplicación de una regla de acuerdo con el principio tecnológico de eficacia, la intervención no produce el efecto previsto, hay que pensar que la teoría es incorrecta, porque no da cuenta ajustada de la intervención. En este sentido la práctica rige la teoría y la tecnología es el punto de partida para cambiar la teoría. En este caso, a partir de la práctica, no sólo se cuestiona la aplicabilidad de la teoría, sino su corrección.

\section{EL MODELO DUAL QUE SEPARA TEORÍA Y PRÁCTICA EN LA FORMACIÓN NO RESUELVE BIEN LA RELACIÓN TEORÍA-PRÁCTICA， PORQUE CADA INTERVENCIÓN PEDAGÓGICA TIENE QUE INTEGRAR CONOCIMIENTO Y ACCIÓN}

A lo largo de los epígrafes anteriores, de manera implícita, he asumido la necesidad de distinguir "ámbito de conocimiento" y "conocimiento del ámbito", distinguir educación y Pedagogía, para saber de qué hablamos en cada caso, pues las Carreras estudian el conocimiento del ámbito y las Facultades se definen por el conocimiento del ámbito, no por el ámbito de conocimiento. Es posible parcelar el conocimiento de la educación en disciplinas y es posible parcelar la educación en ámbitos. El crecimiento del conocimiento de la educación puede generar nuevas disciplinas y nuevos ámbitos. En la carrera de Pedagogía aprendemos a descubrir, inventar e innovar en educación como actividad, como ámbito de realidad y como ámbito de conocimiento, perfeccionando nuestro conocimiento del ámbito. Las disciplinas tienen un lugar específico en este proceso.

La educación como ámbito de realidad es susceptible de ser conocida de diversas formas y cada una de ellas se aplica a la obtención del mejor conocimiento de la educación que es posible. Los principios de investigación pedagógica de objetividad, complejidad objetual, autonomía funcional, complementariedad metodológica y validez-significación avalan esta posición. La educación como ámbito de realidad es susceptible de ser contemplada como acción y como ámbito de conocimiento; la educación como ámbito de realidad es una actividad cognoscible, enseñable, investigable y realizable. La complejidad del objeto "educación” está marcada por la doble condición de ámbito de conocimiento y acción, y no tener esto en cuenta da lugar a la perdida de significación en el conocimiento de la educación.

En la relación teoría-práctica, desde la perspectiva de la mentalidad pedagógica específica y de la mirada pedagógica especializada y asumiendo la práctica educativa como eje fundamental de la investigación teórica de la educación, suelen distinguirse tres posiciones respecto del conocimiento de la educación (Touriñán, 2017; Gil Cantero, 2011):

- Práctica educativa sin teoría: posición que habla de la imposibilidad de alcanzar las generalizaciones teóricas de la ciencia positiva o quedarse en ellas, porque la educación tiene que trascenderlas necesariamente en la práctica. 
- Teoría sin práctica educativa: posición que toma como referencia los trabajos de epistemología aplicada y reivindica la necesidad de hacer conocimiento de la educación, pero, en su afán de justificar la necesidad de conocer, esta posición se olvida de la educación que es el objeto de conocimiento; en esta posición la educación como actividad práctica pasa a un segundo plano y se preocupa más por el tipo de teorías interpretativas más apropiadas para la educación como ámbito de realidad cognoscible.

- Teoría con práctica educativa: posición que asume la complejidad del objeto de conocimiento de la educación y al mismo tiempo reclama para ella el sentido de una actividad práctica, cuya resolución requiere conocimiento vinculado a la práctica y a la consistencia teórica de la intervención.

No pretendo insistir ahora, de nuevo, en la pluralidad de investigación posible sobre el objeto de conocimiento "educación" y su significación, sino de denunciar los errores que se cometen al no defender la doble condición de conocimiento y acción para el objeto "educación" o de aislar y desvincular una condición de la otra. Y en este sentido, mantengo que, en todos aquellos ámbitos de realidad que son una actividad susceptible de ser considerada como conocimiento y acción, se han enfrentado en algún momento al problema del modelo dual en el ámbito universitario.

El modelo dual no se identifica en este trabajo con la modalidad de formación profesional dual que requiere actividad formativa coordinada en centros escolares y en centros de trabajo. El modelo dual se entiende aquí como modelo de formación general que considera separadas la teoría y la práctica, el conocimiento y la acción, de tal manera que la teoría proporcionaría representaciones mentales (conocimiento interpretativo) y la práctica proporcionaría formas de acción.

La contraposición equivocada entre profesores y pedagogos, entre facultades de ciencias de la educación y escuelas de formación de profesores (Magisterio), entre "teóricos" y "prácticos" son ejemplos de la asunción del modelo dual que separa conocimiento y acción. Seguimos teniendo ejemplos muy claros de modelo dual en las artes y en la mentalidad de muchos pedagogos sigue existiendo el modelo dual para separar el estudio del conocimiento y la acción. En las artes, y en cualquier otro campo que sea susceptible de ser visto como actividad humana realizable y como conocimiento de la actividad, se da una relación entre la teoría y la práctica que no debe soslayarse, pero que el modelo dual mantiene, interesadamente, soslayada. El modelo dual defiende que la especialización (tomando como ejemplo la música) en la rama musicológica se lleva a cabo, preferentemente, en las universidades y la relacionada con la producción musical en los conservatorios de música.

En este modelo, la Universidad contemplaría la música como objeto cognoscible, investigable y enseñable, respecto de la manera de conocer y de investigarla; pero no entraría en el conocimiento e investigación de la parte que corresponde a la actividad de producir y crear música (realización de la música como original ejecución, interpretación, comprensión y expresión musical por medio del dominio técnico del instrumento). Para la Universidad, la música sería conocimiento teórico y ámbito de investigación y ambas cosas podrían enseñarse.

Por su parte, el conservatorio superior contemplaría la música como una actividad creativa cuyo dominio técnico y ejecución práctica pueden enseñarse y aprenderse. El objetivo de la educación artística-musical en los conservatorios sería el logro de competencia para saber crear objetos artísticos, utilizando las formas de expresión y los 
instrumentos apropiados de manera que cada alumno pueda ejecutar, expresar, comprender e interpretar música por medio del instrumento idóneo. En cada ámbito artístico puede haber genios, pero el objetivo de la educación artística en los conservatorios no es crear genios, sino preparar buenos técnicos capaces de crear objetos artísticos. Las obras de arte y los genios son otra cosa. Y aun admitiendo que tenemos que crear genios, no se invalida lo que hemos dicho en relación al modelo dual.

En el modelo dual, conocimiento y acción respecto del mismo objeto, están separadas. Se defiende que el Conservatorio hace "artistas-músicos" y la Universidad hace técnicos de investigación y conocimiento del arte en cuestión. A la Universidad le corresponde la "musicología" y al Conservatorio la "música". En ese universo ideal dicotomizado, de la Universidad deberían salir los investigadores de la música creada y del Conservatorio los creadores de música. De la Universidad procederían los especialistas en conocimiento e investigación de música ya realizada y del Conservatorio procederían especialistas en ejecución de música ya realizada y en realización de nueva música.

Es mi opinión que la música, como cualquier otro ámbito de realidad o manifestación creativa humana que implique conocimiento y acción, es una manifestación de creatividad cultural y como tal es cognoscible, enseñable, investigable y realizable (lo cual implica ejecución de la acción, interpretación, comprensión y expresión) y puede ser objeto de racionalidad científico-tecnológica, racionalidad práxica y racionalidad artística (como la educación). Implica las dos vertientes, la "teórica" (conocer, investigar y enseñar a conocer e investigar) que el modelo dual ubica en la Universidad y la "práctica" (realizar música y enseñar a realizarla), que el modelo dual ubica en el Conservatorio.

En mi país, los partidarios del modelo dual mantienen separado el conocimiento y la acción en estos casos comentados. Lo curioso es que en cualquier otra carrera (medicina, derecho o ingenierías, por ejemplo), que tienen componente de realización de acción y de conocimiento, todas las tareas se vinculan en el mismo centro (conocer, investigar, enseñar a conocer e investigar y realizar la actividad práctica de médico, ingeniero químico, etcétera). Los laboratorios y los hospitales para prácticas y las facultades no están desvinculados y disgregados en la formación, tal como lo están Universidad y Conservatorio en el caso comentado. Y por descontado, también es verdad que la mayoría de los creadores de música no salen del conservatorio.

Separar las dos vertientes, conocimiento y acción, no es tan bueno para la formación de futuros profesionales como algunos piensan, aferrándose a posturas separatistas, que sólo pretenden gremialmente mantener su reino de taifas alejado de cualquier aproximación exterior; demasiada endogamia. Los de un centro serán técnicos de interpretación y los del otro centro serán críticos y solo algunos de cualidades geniales, serán artistas. Mientras eso siga así, y en relación con el caso que comentamos, habrá una fractura en la formación derivada de la música como actividad realizable y la música como actividad cognoscible y escuchable.

Como ya he dicho en el epígrafe 3, en todos los ámbitos de realidad que tienen la doble condición de ámbito de conocimiento y de acción se dan siempre tres tipos de funciones: docencia, investigación y funciones de técnico de intervención en el ámbito específico de actividad. Si pensamos en las artes, como ejemplo, distinguimos claramente, la función de docencia en artes, la de investigación en artes, la de técnico de 
apoyo a la realización de un arte (como el gerente de auditorio o el director de festival, entre otros) y la de técnico especialista en la realización de un arte (como el músicoinstrumentista o el director de orquesta, por ejemplo).

Superar el modelo dual es compatible con la existencia de escuelas de especialización y maestrías con itinerarios orientados a la destreza práctica de alto nivel. Está claro que, si distinguimos "ámbito de conocimiento" y "conocimiento de un ámbito", no pensaremos en hacer doctores en saltos de vallas, o en hacer doctores en pintar cuadros o en escribir partituras musicales. Los doctorados se otorgan disciplinarmente por conocimiento del ámbito; hay doctores en artes, no en pintar cuadros; hay doctores en estomatología, no en dientes; hay doctores en educación física, cuyo tema de tesis es el salto de vallas, pero no hay doctores en saltar vallas. Un sistema de educación universitaria es compatible con la existencia de escuelas profesionales del más alto grado de pericia, incluso con un último nivel sólo para alumnos geniales, que serán artistas virtuosos. Pero tan obvio como esto es que, en la educación universitaria, nos alejamos del sentido de la relación teoría-práctica, si aceptamos que un especialista en musicología termina la carrera y no tiene que saber, por título, notación musical, análisis e interpretación y que un alumno de conservatorio superior, que se reconoce como educación universitaria, no sabe, por titulación, nada de pensamiento artístico y musicología, más allá del instrumento de interpretación.

Las Escuelas profesionales no son facultades universitarias. El conocimiento y la acción constituyen ámbito disciplinar en la educación universitaria. Su separación abre una fractura entre la teoría y la práctica que distorsiona la racionalidad epistemológica. La integración de teoría y práctica en la educación universitaria no es incompatible con el desarrollo profesional de intérpretes y artistas. Pero exige imponer racionalidad en las decisiones de política educativa y respetar la racionalidad epistemológica de la relación teoría-práctica en la intervención pedagógica. que siempre exige conocimiento y acción en la realización del acto. Para realizar algo hay que ejecutar mediante la acción concreta, lo comprendido e interpretado, expresándolo.

\section{LA FUNCIÓN PEDAGÓGICA GENERA INTERVENCIÓN DESDE LAS ACTIVIDADES COMUNES INTERNAS Y EXTERNAS}

En educación realizamos muchas acciones con el objeto de influir en el educando y lograr el resultado educativo. Son siempre acciones mediadas de un sujeto con otro o de un sujeto consigo mismo. Y todas esas acciones, que tienen que respetar la condición de agente del educando, buscan provocar la actividad del educando. En su uso más común, "actividad" se entiende como estado de actividad, es actividad-estado: la actividad es el estado en que se encuentra cualquier persona, animal o cosa que se mueve, trabaja o ejecuta una acción en el momento en que lo está haciendo (decimos: este niño está pensando). Este uso hace referencia también a la capacidad que tenemos de acción en esa actividad y por eso decimos este niño ha perdido actividad (ahora piensa menos, ha dado un bajón). Por ser el uso más común del término "actividad" como estado y capacidad, lo denominamos actividad común y se da en todas las personas porque en todas las personas hay actividad como estado y como capacidad de hacer (Touriñán, 2014 y 2020a). 
Respecto de la actividad común, hemos de decir que la investigación actual distingue entre acciones ejecutadas para obtener un resultado y acciones cuyo resultado es la propia acción. Así, por ejemplo, la acción de resolver un problema tiene por resultado algo "externo" a la acción: obtener una solución (estudiar tiene como resultado dominar un tema). En todos estos casos, no se puede ejecutar la acción de resolver el problema y tenerlo resuelto. Sin embargo, no puedo sentir sin estar sintiendo, pensar sin estar pensando, proyectar sin estar proyectando, etc. Las primeras son actividades externas y las segundas son actividades internas. Nosotros, desde ahora, hablaremos respecto de la educación, de actividad común (actividad estado y capacidad) interna (resultado es la propia acción: pensar, sentir, querer, operar, proyectar y crear) y externa (actividad estado y capacidad, cuyo resultado es externo a la propia acción, pero vinculado conceptualmente a la actividad en sí: tengo capacidad lúdica, tengo capacidad de estudiar, tengo capacidad de trabajar, de intervenir, de indagar-explorar y tengo capacidad de relacionar).

Desde la perspectiva de la actividad común interna podemos hacer una taxonomía de las actividades tomando como referente el agente educando. Todos convenimos en que, cuando nos educamos, sea auto o heteroeducación, nuestra condición humana nos permite realizar las siguientes actividades comunes internas: pensar, sentir afectivamente (tener sentimientos), querer objetos o sujetos de cualquier condición, operar (elegir-hacer cosas procesando medios y fines), proyectar (decidir-actuar sobre la realidad interna y externa orientándose) y crear (construir algo desde algo, no desde la nada, simbolizando la notación de signos: darse cuenta de algo -notar- y darle significado - significar-, construyendo símbolos de nuestra cultura). Nadie se educa sin estar pensando, sintiendo, queriendo, etc. Educarse es mejorar siempre esa actividad común interna y saber usarla para actividades especificadas instrumentales que nos hacen ser cada vez más capaces de decidir y realizar nuestros proyectos.

También convenimos en que, cuando nos educamos, nuestra condición humana nos permite realizar las siguientes actividades comunes externas: juego, trabajo, estudio, intervención, indagación-exploración y relación (de amigo, familiar, de pareja, social, etc.). Son actividades comunes (estado y capacidad), porque tengo capacidad para el estudio, el juego el trabajo, la exploración, la intervención y la relación. Y son actividades comunes externas, porque tienen necesariamente un resultado que se va a obtener, que es externo a la actividad en sí, pero que está vinculado conceptualmente como meta a la actividad y la caracteriza como rasgo identitario. De ahí que digamos que estudiar es disponer y organizar información escrita "para" su dominio (dominar o saber el tema de estudio); el dominio-saber del tema de estudio es el resultado externo de la actividad y ese resultado es la finalidad que identifica el estudio, con independencia de que yo pueda utilizar el estudio para hacer un amigo, para ayudar altruistamente a otro, para robar mejor, etcétera, que son usos de la actividad como especificaciones instrumentales de ella (Touriñán, 2016).

Como actividad común externa, estudiar, por ejemplo, tiene un fin propio vinculado a esa actividad de manera conceptual y lógica (el fin propio de estudiar es dominarsaber aquello que se estudia: una información, un contenido o la propia técnica de estudio). Pero, además, como actividad común externa, estudiar puede convertirse en actividad instrumental especificada para otras finalidades, son finalidades especificadas y externas a la actividad en sí, pero vinculadas a la actividad de estudiar de manera 
empírica o experiencial (estudiar se convierte en actividad instrumental especificada, porque podemos estudiar para robar, para hacer amigos, para ayudar a otro, para educarse, etcétera) (Touriñán, 2019a).

Es un hecho que las actividades comunes se usan propedéuticamente para finalidades educativas, pero también pueden usarse para otras finalidades. Las actividades comunes pueden ser usadas para realizar actividades especificadas instrumentales y tienen valor propedéutico; son preparatorias para algo posterior. Y esto es así, por una parte, porque todo lo que usamos como medio en una relación medio-fin, adquiere la condición propia de los medios en la relación (el medio es lo que hacemos para lograr el fin y el fin es un valor elegido como meta en la relación medios-fines) y, por otra parte, es así, porque el medio muestra su valor pedagógico en las condiciones que le son propias, ajustando el medio al agente, a la finalidad educativa y a la acción, en cada circunstancia (Touriñán, 2020b).

Desde la perspectiva de la actividad común interna podemos decir que la actividad es principio de la educación, porque nadie se educa sin estar pensando, sintiendo, queriendo, etc. Y desde el punto de vista de la actividad común externa podemos decir que hacemos muchas actividades cuya finalidad es "educar". Siempre, desde la perspectiva del principio de actividad como eje directriz de la educación: educamos con la actividad respetando la condición de agente (Touriñán, 2015).

Si esto es así, se sigue que los medios tienen que ajustarse a la actividad del sujeto y al significado de educación. Son medios para un sujeto concreto que piensa, siente, quiere, opera, proyecta y crea. Son medios para realizar actividad, jugando, trabajando, estudiando, indagando, interviniendo y relacionándose. Pero el agente realiza esas actividades para educarse: no piensa de cualquier manera, sino de la que se va construyendo para educarse y actuar educadamente, y así sucesivamente con todas las actividades. Se sigue, por tanto, que cualquier medio no es "el medio" para un sujeto concreto; en la acción educativa, el sujeto-educando actúa con los medios internos que tiene y con los medios externos que han sido puestos a su disposición. Y todos esos medios solo son medios educativos, si sirven para educar a ese sujeto-educando. Los medios no son exactamente los mismos, si quiero formar el sentido crítico, o si quiero educar la voluntad para producir fortaleza de ánimo. Precisamente por eso se explica la tendencia a centrarse en los medios específicos y particulares de una acción, olvidándose de los medios comunes y compartidos con otras actividades educativas.

La actividad está presente en toda educación: desde una perspectiva, como principio de intervención y, desde otra, como principio de educación. Y precisamente por ser esto así, se explica que la actividad se convierta en el principio-eje vertebrador de la educación y represente el sentido real de la educación como actividad dirigida al uso y construcción de experiencia valiosa para generar actividad educada. Usamos la actividad común para educar, educamos las competencias adecuadas de la actividad común y esperamos obtener actividad educada. En definitiva, usamos la actividad de manera controlada para lograr actividad educada y educar la actividad por medio de las competencias adecuadas (Touriñán, 2016).

El principio de actividad, ni es pasividad, ni es activismo; es uso de la actividad de manera controlada para actuar educadamente. $\mathrm{Y}$ de este modo, la actividad y el control son principios de la intervención pedagógica, derivados de la condición de agente que tiene que construirse a sí mismo y reconocerse con el otro y lo otro en un entorno cultural diverso de interacción, por medio de los valores que ha de elegir, 
comprometerse, decidir y realizar, ejecutando por medio de la acción concreta lo comprendido e interpretado de la relación medio-fin, expresándolo, de acuerdo con las oportunidades.

Esto es así, porque, por principio de actividad, nadie se educa sin estar pensando, sintiendo, queriendo, operando, proyectando y sin estar interpretando símbolos de nuestra cultura creativamente. Nos educamos con la actividad común interna. Pero, además, nos educamos por medio de la actividad común externa (estudiando, jugando, trabajando, indagando-explorando, interviniendo y relacionándonos con el yo, el otro y lo otro), porque al ejercer una concreta actividad común externa activamos las capacidades comunes internas, las entrenamos, las ejercitamos, las ejercemos y las mejoramos para hacer bien cada actividad común externa. La actividad común externa, por principio de actividad, activa la actividad común interna en cada ejecución concreta de la actividad común externa, sea esta jugar, estudiar, trabajar, indagar, intervenir o relacionar. Al ejecutar la actividad común externa, mejoramos y entrenamos las actividades-capacidades internas: sin la actividad es imposible educar y gracias a ella se hace posible que el educando sea agente actor y cada vez mejor agente autor de su propios proyectos y actos.

El principio de actividad permite afirmar en Pedagogía que la actividad común externa (por ejemplo, jugar) activa la actividad común interna de pensar, sentir, querer, operar, proyectar y crear, pero eso no significa caer en el activismo: la actividad por la actividad no educa; pensar de cualquier manera no es educarse, pues educarse, como mínimo, requiere que, al pensar, se mejore el hábito y el modo de pensar.

Por todo eso, la educación es un problema de todos y todos contribuimos a ella porque todos nos formamos y tenemos que usar la actividad común para educar y educarnos y sin ella no es posible hacerlo.

\section{CONSIDERACIONES FINALES: LA ACTIVIDAD COMÚN Y LA RELACIÓN TEORÍA-PRÁCTICA SON FOCOS PARA RESOLVER PROBLEMAS DE EDUCACIÓN DESDE LA PEDAGOGÍA (BIEN COMO DISCIPLINA CIENTÍFICA MATRIZ, BIEN COMO DISCIPLINAS SUSTANTIVAS INDIVIDUALIZADAS O BIEN COMO DISCIPLINAS APLICADAS)}

Como ya he dicho en el epígrafe 6.4 de este trabajo, las disciplinas científicas pueden ser entendidas como disciplinas generadoras dentro de la corriente autónoma del conocimiento de la educación. Las disciplinas generadoras son las que, bajo criterio ontológico y epistemológico, generan conceptos propios de la parcela de realidad que estudian con autonomía funcional (Forma de conocimiento + ámbito de realidad para conocer + autonomía funcional metodológica). Una disciplina que tiene conceptos propios puede aplicarse a la interpretación de otros ámbitos de realidad siempre que esos ámbitos se ajusten a esos conceptos en alguna medida. De este modo, la disciplina generadora se convierte en teoría interpretativa del ámbito en el que se aplica. Desde los conceptos de la disciplina generadora interpretamos el ámbito al que se aplica. Desde esta perspectiva de aproximación, los conceptos propios de la disciplina Pedagogía pueden utilizarse para interpretar ámbitos en los que la educación es el contexto de 
interpretación y así la Pedagogía es generadora de disciplinas aplicadas (pedagogía familiar, pedagogía laboral, pedagogía social, etcétera).

Existen preocupaciones y estudios acerca de la educación que se resuelven en términos de disciplinas generadoras (con conceptos aplicables a educación y la interpretan desde esos conceptos), tales como la Psicología, la Sociología, la Biología, etc. La educación puede ser interpretada en términos de motivación y comportamiento, en términos de salud y vida, en términos de relaciones sociales, etc. En estos casos, la educación es un ámbito de realidad para estudiar que se resuelve en teorías interpretativas o investigaciones aplicadas, hablamos en este caso de psicología de la educación, biología de la educación, sociología de la educación, etc.

Y si esto es así, se sigue que lo importante es, en nuestro caso, ir desde la Pedagogía General a las Pedagogías aplicadas, porque muy diversos ámbitos de conocimiento pueden ser interpretados en términos de la disciplina generadora, como disciplinas aplicadas, siempre que ese ámbito sea susceptible de ser interpretado desde los conceptos que la disciplina generadora ha creado. Es un hecho que hay pedagogía (familiar, laboral, social, ambiental, carcelaria, gerontológica, de las artes, de la literatura, etcétera), porque los ámbitos de conocimiento (la familia, el trabajo, lo social, el ambiente, etcétera), pueden ser interpretados en conceptos construidos por la Pedagogía para el ámbito educación. La clave, desde la pedagogía aplicada, es transformar el ámbito de conocimiento al que se enfoca, interpretándolo en términos de Pedagogía, para, de ese modo, construir el ámbito de educación, hacer el diseño educativo y generar la intervención que materializa el contenido de la expresión "educar CON" cada uno de esos ámbitos (Touriñán, 2017b y 2020c).

Y para materializar el contenido de la expresión "educar CON", desde la disciplina aplicada, o desde la disciplina científica matriz, o desde la disciplina académica sustantiva que se desgaja de ella, establecemos el conocimiento que relaciona teoría y práctica en cada caso y aseguramos, por medio de la capacidad de resolución de problemas en cada intervención, el uso educativo de la actividad común interna y externa.

Finalmente, como hemos expuesto en el epígrafe dedicado a la función pedagógica, nos educamos con la actividad común interna (pensar, sentir afectivamente, querer, operar, proyectar y crear). Pero, además, nos educamos por medio de la actividad común externa (estudiando, jugando, trabajando, indagando-explorando, interviniendo y relacionándonos con el yo, el otro y lo otro), porque al ejercer una concreta actividad común externa activamos las capacidades comunes internas, las entrenamos, las ejercitamos, las ejercemos y las mejoramos para hacer bien cada actividad común externa. La actividad común externa, por principio de actividad, activa la actividad común interna en cada ejecución concreta de la actividad común externa, sea esta jugar, estudiar, trabajar, indagar, intervenir o relacionar. Al ejecutar la actividad común externa, mejoramos y entrenamos las actividades-capacidades internas: sin la actividad es imposible educar y gracias a ella se hace posible que el educando sea agente actor y cada vez mejor agente autor de su propios proyectos y actos.

Hay que educar, y esto implica que interpretamos el área de experiencia cultural desde la mentalidad pedagógica específica y desde la mirada pedagógica especializada. Por una parte, hacemos visión crítica de nuestra actuación, ajustada a principios de educación y de intervención pedagógica y, por otra parte, representamos mentalmente la acción de educar desde la perspectiva de la relación teoría-práctica. 


\section{BIBLIOGRAFÍA}

Avanzini, G. (1977). La Pedagogía del siglo XX. Madrid: Narcea.

Bachelard, G. (1973). Epistemología. Barcelona: Anagrama.

Bachelard, G. (1974). La formación del espíritu científico. Buenos Aires: Siglo XXI.

Belth, M. (1971). La educación como disciplina científica. Buenos Aires: El Ateneo.

Berliner, D.C. (1986). In Pursuit of the Expert Pedagogue. Educational Researcher, 15, 5-14.

Bertalanffy, L.Von (1976). Teoría General de Sistemas. México: Fondo de Cultura Económica.

Bertalanffy, L.Von (1979). Perspectivas en la teoría general de sistemas. Madrid: Alianza Universidad.

Biesta, G., Allan, J. y Edwards, R. (Eds.) (2014). Making a Difference in Theory: The Theory Question in Education and the Education Question in Theory. Londres/Nueva York: Routledge.

Boavida, J. y García del Dujo, A. (2007). Teoría da Educaçao. Contributos Ibéricos. Coimbra: Imprenta da Universidade de Coimbra.

Bowen, J. y Hobson, P.R. (1979). Teorías de la educación. México: Limusa.

Broudy, H.S. (1977). Types of Knowledge and Purpose of Education. En R.C. Anderson et al., Schooling and the Acquisition of Knowledge (pp. 1-17). Nueva Jersey: Laurence Erlbaum Associates.

Brubacher, J.S. (1962). Modern Philosophies of Education. New York: McGraw-Hill.

Bunge, M. (1981). La investigación científica. Su estrategia y su filosofía. Barcelona: Ariel. $6^{\mathrm{a}}$ ed.

Bunge, M. (1985). Treatise on Basic Philosophy. Vol.7. Part. II. Holland: Reidel, Dordrecht.

Capitán, A. (1979). Teoría de la educación. Zaragoza: Edelvives.

Carr, W. (2006). Education without Theory. British Journal of Educational Studies, 534(2), 136159.

Carr, W. y Kemmis, S. (1988). Teoría crítica de la enseñanza. La investigación-acción en la formación del profesorado. Barcelona: Martínez Roca.

Castillejo, J.L. (1985). Sugerencias para una teoría de la ciencia pedagógica. En P. Aznar et al., Conceptos y propuestas (II). Teoría de la Educación (pp. 45-56). Valencia: Nau Llibres.

Castillejo J.L. y Colom, A.J. (1987). Pedagogía Sistémica. Barcelona: Narcea.

Colom, A.J. (1983). La Teoría de la Educación y la oferta de la Teoría de Sistemas generales. En la Obra Conjunta Epistemología y Pedagogía (pp. 108-155). Madrid: Anaya.

Colom, A.J. (1986). Pensamiento tecnológico y Teoría de la Educación. En la Obra Conjunta Tecnología y Educación (pp. 13-30). Barcelona: CEAC.

COMISION (1986). Documento de bases para la elaboración del estatuto del profesorado. Escuela Española (2.802, de 6 de febrero).

Churchman, W.C. (1961). Prediction and Optimal Decision: Philosophical Issues of a Science of Values. Nueva Jersey: Englewood Cliffs.

Davis, W.K. (1987). Educational Research in the Professions: Paradigms, Peer Review and Promise. Professions Education Research Notes, 9(1), 4-9.

Denison, E.F. (1968). The Sources of Economics Growth in the United States and the Alternatives Before Us. Nueva York: Conmittee for Economic Development.

Escolano, A. (1980). Diversificación de profesiones y actividades educativas. Revista Española de Pedagogía, 147, 83-97.

Escolano, A. (1983). La investigación pedagógica en España. Aproximación bibliométrica. En J. Basabe et al., Ensayos de epistemología y pedagogía. Madrid: Anaya.

Etzioni, A. (1964). Modern Organization. Nueva Jersey: Englewood Cliffs.

Fermoso, P. (1976). Teoría de la educación. Madrid: Agulló.

Fullat, O. (1979). Filosofías de la Educación. Barcelona: CEAC.

Gage, N.L. (1963). Handbook of Research on Teaching. Chicago: Rand McNally.

García Aretio, L. (1989). La educación. Teorías y conceptos. Madrid: Paraninfo. 
García Aretio, L., Ruiz Corbella, M. y García Blanco, M. (2009). Claves para la educación. Actores, agentes y escenarios en la sociedad actual. Madrid: Narcea.

García Carrasco, J. (1980). Ciencias de la educación y profesiones pedagógicas. Problemas académicos y curriculares. VII Congreso Nacional de Pedagogía. Vol. I. Madrid: Sociedad Española de Pedagogía.

García Carrasco, J. (1983). La ciencia de la educación. Pedagogos ¿para qué? Madrid: Santillana.

García Carrasco, J. (Coord.) (1984). Teoría de la Educación. Diccionario de Ciencias de la Educación. Madrid: Anaya.

García Carrasco, J. (2016) Teoría de la educación, en Diccionario Iberoamericano de Filosofía de la educación. México: Fondo de Cultura económica. Disponible en: http://fondodeculturaeconomica.com/dife/definicion.asp $x$ ? $l=$ T\&id $=26 \& w=$

García Carrasco, J. y García del Dujo, A. (2001). La Teoría de la Educación en la encrucijada. Teoría de la Educación. Revista Interuniveristaria, 13, 15-43.

García Garrido, J.L. (1984). Sistemas educativos de hoy. Madrid: Dykinson.

García Hoz, V. (1970). Principios de Pedagogía Sistemática. Madrid: Rialp, $5^{\text {a ed. }}$

Gil Cantero, F. (2011). "Educación con teoría". Revisión pedagógica de las relaciones entre la teoría y la práctica educativa. Teoría de la Educación. Revista Interuniversitaria, 23(1), 1943.

Gimeno, J. (1982a). La integración de la teoría del aprendizaje en la teoría y práctica de la enseñanza. En A. Pérez Gómez y J. Almaraz, Lecturas de aprendizaje y enseñanza (pp. 467469). Madrid: Zero.

Gimeno, J. (1982b). La formación del profesorado en la universidad. Las escuelas universitarias de formación del profesorado de E.G.B. Revista de Educación, 30(269), 77-99.

González Álvarez, A. (1977). Filosofía de la educación. Buenos Aires: Troquel.

Hirst, P.H. (1966). Educational Theory. En J.W. Tibble, The Study of Education (pp. 29-58). Londres: Routledge and Kegan Paul.

Hirst, P.H. (1974). Knowledge and the Curriculum. A Collection of Philosophical Papers. Londres: Routledge and Kegan Paul.

Husen, T. (1979). General Theories in Education. A Twenty-Five Years Perspective. International Review of Education, 25(2-3), 199-219.

Husen, T. (1988). Research Paradigms in Education. En J.P. Keeves: Educational Research Methodology and Measurement, an International Handbook (pp. 17-20). Londres: Pergamon Press

Keeves, J.P. (1988). Educational Research, Methodology and Measurement, an International Handbook. Londres: Pergamon Press.

Kindelberger, J. (1965). Economic Development. Nueva York: Mac-Graw Hill.

Khun, T.S. (1979). La estructura de las revoluciones científicas. México: Fondo de Cultura Económica.

Khun, T.S. (1978). Segundos pensamientos sobre paradigmas. Madrid: Tecnos.

Luhman, N. (1983). Fin y racionalidad de los sistemas. Sobre la función de los fines en los sistemas sociales. Madrid: Editora Nacional.

Marín Ibáñez, R. (1983). Medio siglo de Pedagogía General. Revista Española de Pedagogía, 41(159), 9-24.

Masterman, M. (1970). The Nature of a Paradigm. En I. Lakatos y A. Musgrave (Eds.), Criticism and the Growth of Knowledge (pp. 59-90). London: Cambridge University Press.

Mialaret, G. (1977). Las Ciencias de la Educación. Barcelona: Oikos-Tau.

Mitter, W. (1981). ¿Ciencias de la educación o ciencia de la educación? Algunas consideraciones sobre una cuestión básica. Perspectivas Pedagógicas, 12(47-48), 23-35.

Moore, P.W. (1980). Introducción a la Teoría de la Educación. Madrid: Alianza Universidad, (fecha $1^{\text {a }}$ ed. 1974).

Morin, E. (1984). Ciencia con consciencia. Barcelona: Anthropos. 
Novak, J. (1977). The Theory of Education. Nueva York, Ithaca: Cornell University Press.

O.C.D.E. (1968). The Impact of Science and Technology on Social and Economic Development. París.

O'Connor, D. J. (1971). Introducción a la filosofía de la educación. Buenos Aires: Paidós.

Palop, P. (1981). Epistemología genética y filosofía. Barcelona: Ariel.

Pérez Alonso-Geta, P. (1985). Los Congresos Nacionales de Pedagogía. Valencia: Nau-Llibres.

Peters, D.P. y Ceci, S.J. (1982). Peer Review Practices of Psychological Journals: The Date of Published Articles Submitted Again. Behavioral Brain Science, 5(2). 187-195.

Piaget, J. (1977). Biología y conocimiento. Madrid: Siglo XXI, 4ª ed.

Pring, R. (2014). From Disguised Nonsense to Patent Nonsense: Thinking Philosophically. Revista Española de Pedagogía, 72(258), 231-248.

Quintana, J.M. (1978). El estatuto epistemológico de las ciencias de la educación. En A. Escolano et al., Epistemología y Educación (pp. 92-118). Salamanca: Sígueme.

Quintana, J.M. (1983). Pedagogía, ciencia de la educación y ciencias de la educación. En J. Basabe Barcala y col., Estudios sobre epistemología y Pedagogía (pp. 75-107). Madrid: Anaya.

Rabazas. T. (Coord.) (2014). El conocimiento teórico de la educación en España. Evolución y consolidación. Madrid: Síntesis.

Rey, A. (1959). La ciencia oriental antes de los griegos. México: Uteha.

Rodríguez Martínez, A. (1989). Conocimiento de la educación, función pedagógica y política educativa. Tesis doctoral. Facultad de Filosofía y Ciencias de la Educación de la Universidad de Santiago de Compostela (Editada en microficha por el Servicio de Publicaciones e Intercambio Científico de la Universidad de Santiago de Compostela en 1990, con el no 82). Santiago de Compostela.

Rodríguez Martínez, A. (2006). Conocimiento de la educación como marco de interpretación de la Teoría de la Educación como disciplina. Tendencias pedagógicas, 11, 31-54.

Sanders, O. y Mcpeck, J. (1976). Theory into Practice or Vice Versa. Comments on an Educational Antinomy. The Journal of Educational Thought, 10(3), 188-193.

Sarramona, J. (1985). ¿Qué es la Pedagogía? Una respuesta actual. Barcelona: CEAC.

Schulman, L.S. (1986). Paradigms and Research Programs in the Study of Teaching: A Contemporary Perspective. En M.C. Wittrock, Handbook of Research on Teaching (pp. 3-6). Nueva York: MacMillan.

Schumpeter, M.A. (1949). The Theory of Economic Development. Cambridge: Harvard University Press.

SI(e)TE. Educación (2018). La Pedagogía, hoy. Santiago de Compostela: Andavira.

Simon, H.A. (1957). Models of Man, Social and Rational: Mathematical Essays on Rational Human Behaviour in a Social Setting. Londres: Longman.

Simon, H.A. (1964). On the Concept of Organizational Goal. Administrative Science Quarterly, 9, 1-22.

Smeyers, P. (2010). Repensar la filosofía de la educación. Teoría de la Educación. Revista Interuniversitaria, 22(1), 117-140.

Strong, E.W. (1966). Procedures and Metaphysics. Olms: Hildesheim.

Suchodolsky, B. (1979). Tratado de Pedagogía. Barcelona: Península.

Toulmin, S., Rieke, R. y Janik, A. (1979). An Introduction to Reasoning. Londres: Collier McMillan.

Touriñán, J.M. (1984). La imagen social de la Pedagogía. Bordón, 253, 600-630.

Touriñán, J.M. (1987a). Estatuto del profesorado, función pedagógica y alternativas de formación. Madrid: Escuela Española.

Touriñán, J.M. (1987b). Teoría de la Educación. La educación como objeto de conocimiento. Madrid: Anaya.

Touriñán, J.M. (1987c). Función pedagógica y profesionales de la educación. Bordón, 266, 31-51. 
Touriñán, J. M. (1988-89). El conocimiento pedagógico: Corrientes y parámetros. Revista Educar, 14-15, 81-92.

Touriñán, J.M. (1989). Teoría de la Educación. Identificación de la asignatura y competencia disciplinar. Revista de Ciencias de la Educación, 35(137), 7-36.

Touriñán, J.M. (1990). Profesionalización como principio del sistema educativo y función pedagógica. Revista de Ciencias de la Educación, 36(141), 9-23.

Touriñán, J.M. (1991). Conocimiento de la Educación y Función Pedagógica: El sentido de la Competencia profesional. Revista de Teoría de la Educación, 3, 11-28.

Touriñán, J.M. (2013a). El significado de la función pedagógica y la necesidad de generar principios de acción. Revista Española de Pedagogía, 71(54), 29-47.

Touriñán, J.M. (2013b). Conocer, enseñar y educar no significan lo mismo. El carácter y el sentido de la educación como referentes de su significado desde la mirada pedagógica. Teoría de la Educación. Revista Interuniveristaria, 25(1), 25-46.

Touriñán, J.M. (2013c). ¿Enseñar áreas culturales o educar con las áreas culturales? En Grupo SI(e)TE. Educación, Desmitificación y crítica de la educación actual (pp. 57-92). Barcelona: Octaedro.

Touriñán, J.M. (2014). Dónde está la educación. Actividad común interna y elementos estructurales de la intervención. A Coruña: Netbiblo. Disponible en: http://dondestalaeducacion.com/

Touriñán, J.M. (2015). Pedagogía mesoaxiológica y concepto de educación. Santiago de Compostela: Andavira. Hay $2^{\text {a }}$ edición disponible en 2016.

Touriñán, J.M. (2016). Pedagogía general. Principios de educación y principios de intervención. A Coruña: Bello y Martínez.

Touriñán, J.M. (2017a). Mentalidad pedagógica y diseño educativo. De la pedagogía general a las pedagogías aplicadas en la función de educar. Santiago de Compostela: Andavira.

Touriñán, J.M. (2017b). Educar con las artes. Pedagogía general y aplicada a la construcción de las artes como ámbito de educación. Colombia: Redipe.

Touriñán, J.M. (2018a). Concepto de educación y conocimiento de la educación. The Concept of Education and the Knowledge of Education. Colombia-Nueva York: Redipe (BowkerBooks).

Touriñán, J.M. (2018b). La significación del conocimiento de la educación y su capacidad de resolución de problemas: fundamentos desde el conocimiento pedagógico. Revista Boletín Redipe, 7(1), 25-61.

Touriñán, J.M. (2019a). Estudiar es actividad común externa y siempre educamos con la actividad. Una aproximación desde la perspectiva mesoaxiológica. Teoría de la Educación. Revista Interuniversitaria, 31(2), 7-31.

Touriñán, J.M. (2019b). La Pedagogía no es la Filosofía y la Filosofía no es la Filosofía de la Educación. Revista Boletín Redipe, 8(5), 17-84.

Touriñán, J.M. (2020a). Función pedagógica, competencia técnica y transferencia de conocimiento. La perspectiva mesoaxiológica de la Pedagogía. Colombia-Nueva York: Redipe (Bowker-Books).

Touriñán, J.M. (2020b). Los medios y su valor pedagógico en la relación educativa. En A. Medina, A. de la Herrán y M. ${ }^{a}$ C. Domínguez, Hacia una Didáctica humanista (pp. 199268). Colombia-Madrid: Redipe (Bowker Books in print)-UNED.

Touriñán, J.M. (2020c). Alcance de ‘Teoría de la Educación' en la carrera de Pedagogía. Revista Boletín Redipe, 9(4), abril, 25-89.

Touriñán, J.M. y Longueira, S. (Coords.) (2016). Pedagogía y construcción de ámbitos de educación. La función de educar. Colombia, Cali: REDIPE-RIPEME.

Touriñán, J.M. y Rodríguez, A. (1993). Significación del conocimiento de la educación. Revista de Educación, 302, 165-192.

Touriñán, J.M. y Sáez, R. (2015). La mirada pedagógica. Teoría de la educación, metodología y focalizaciones. Santiago de Compostela: Andavira. 
Relación teoría-práctica y actividad común como focos para resolver problemas de educación: la significación del conocimiento de la educación no ampara el modelo dual

Vázquez Gómez, G. (1981). Apuntes bibliográficos de la ciencia pedagógica. Revista Española de Pedagogía. 39(153), 9-36.

Vázquez Gómez, G. (1984). La Pedagogía General, ¿Una teoría general de la educación? Problemática actual y perspectivas de futuro. Cincuentenario de los estudios universitarios de Pedagogía. Madrid: Universidad Complutense de Madrid.

Walton, J. (1971). Introduction to Education: A Substantive Discipline. Waltham, Massachusetts: Xerox College Press.

Wilden, A. (1972). Sistema y estructura. Madrid: Alianza Universidad.

Wittrock, M.C. (Ed.) (1986). Handbook of Research on Teaching. Nueva York: MacMillan. 